This item was submitted to Loughborough's Research Repository by the author.

Items in Figshare are protected by copyright, with all rights reserved, unless otherwise indicated.

\title{
Geomorphic evolution of the Qingshuigou channel of the Yellow River Delta in response to changing water and sediment regimes and human interventions
}

\section{PLEASE CITE THE PUBLISHED VERSION}

https://doi.org/10.1002/esp.4884

\section{PUBLISHER}

Wiley

\section{VERSION}

AM (Accepted Manuscript)

\section{PUBLISHER STATEMENT}

This is the peer reviewed version of the following article: Han, S. ... et al., (2020). Geomorphic evolution of the Qingshuigou channel of the Yellow River Delta in response to changing water and sediment regimes and human interventions. Earth Surface Processes and Landforms, 45 (10), pp.2350-2364, which has been published in final form at https://doi.org/10.1002/esp.4884. This article may be used for non-commercial purposes in accordance with Wiley Terms and Conditions for Use of Self-Archived Versions.

\section{LICENCE}

CC BY-NC-ND 4.0

\section{REPOSITORY RECORD}

Han, Shasha, Stephen Rice, Guangming Tan, Kairong Wang, and Shan Zheng. 2020. "Geomorphic Evolution of the Qingshuigou Channel of the Yellow River Delta in Response to Changing Water and Sediment Regimes and Human Interventions". Loughborough University. https://hdl.handle.net/2134/12280400.v1. 
Han Shasha (Orcid ID: 0000-0002-2036-7112)

Rice Stephen (Orcid ID: 0000-0003-0737-9845)

Geomorphic evolution of the Qingshuigou channel of the Yellow River Delta in response to changing water and sediment regimes and human interventions

\section{RUNNING HEAD: Geomorphic evolution of the Qingshuigou channel}

Shasha Han ${ }^{a, c}$, Stephen Rice ${ }^{b}$, Guangming Tan ${ }^{\star a}$, Kairong Wang ${ }^{c}$ and Shan Zheng ${ }^{a}$

a State Key Laboratory of Water Resources and Hydropower Engineering Science,

Wuhan University, Hubei 430072, China

b Loughborough University, Loughborough, Leics., UK, LE11 3TU

cYellow River Institute of Hydraulic Research, Yellow River Conservancy Commission, Zhengzhou, Henan 450003, China

This article has been accepted for publication and undergone full peer review but has not been through the copyediting, typesetting, pagination and proofreading process which may lead to differences between this version and the Version of Record. Please cite this article as doi: 10.1002/esp.4884 
${ }^{*}$ Corresponding author.

Guangming Tan

State Key Laboratory of Water Resources and Hydropower Engineering Science, Wuhan University, Hubei 430072, China

Tel: (86) 13707134737

E-mail: tangm@vip.163.com

\section{Abstract}

Delta channels are important landforms at the interface of sediment transfer from terrestrial to oceanic realms and affect large, and often vulnerable, human populations. Understanding these dynamics is pressing because delta processes are sensitive to climate change and human activity via adjustments in, for example, mean sea level, and water and sediment regime. Data collected over a 40 -year period along a $110 \mathrm{~km}$ distributary channel of the Yellow River Delta offers an ideal opportunity to investigate morphological responses to changing water and sediment regimes and intensive human activity. Complementary data from the delta front provide an opportunity to explore the interaction between delta channel geomorphology and delta-front erosionaccretion patterns. Cross-section dimensions and shape, longitudinal gradation and a sediment budget are used to quantify spatial and temporal morphological change along the Qingshuigou channel. Distinctive periods of channel change are identified, and analysis provides a detailed understanding of the temporal and spatial adjustments of the channel to specific human interventions, including two artificial channel diversions and changes in water and sediment supply driven by river management, and downstream delta-front development. Adjustments to the 
diversions included a short-lived period of erosion upstream and significant erosion in the newly activated channel, which progressed downstream. Channel geomorphology widened and deepened during periods when management increased water yield and decreased sediment supply, and narrowed and shallowed during periods when management reduced water yield and the sediment load. Changes along the channel are driven by both upstream and downstream forcing. Finally, there is some evidence that changing delta-front erosion-accretion patterns played an important role to the geomorphic evolution of the deltaic channel; an area that requires further investigation.

Keywords: Qingshuigou channel; channel bed adjustment; Yellow River Delta; human intervention; water and sediment regime

\section{Introduction}

\subsection{Deltas and delta channels}

Deltaic channels are the final link in the cascade of terrestrial sediments into the ocean, which makes them an essential part in deltaic systems (Syvitski \& Saito, 2007; Tejedor et al., 2015; Nienhuis et al., 2016). Located in the transition zone at the landocean margin, the geomorphic evolution of deltaic systems depends on the fluvial input, particularly water discharge and sediment load, as well as coastal conditions including tidal regime, wave energy and littoral currents (Walling \& Fang, 2003; Wang et al., 2006; Fagherazzi et al., 2015; Jiang et al., 2017). The interactions among these factors influence patterns of sediment deposition and erosion in delta channels and on delta fronts (both the subaerial and subaqueous parts of delta fronts). Moreover, it is likely that the evolution of channel and delta morphology is intimately connected so that change in either part is a potential cause of change in the other (Wang et al., 2006; 
Syvitski \& Saito, 2007). The geomorphological dynamics and behaviour of deltas and their distributary channels affect large and often vulnerable human populations, making full understanding particularly pressing (Nittrouer \& Viparelli, 2014; Jiang et al., 2017).

Previous studies have revealed that many large river systems in the world have been dramatically altered during the Anthropocene due to climate change and human activities (Frihy \& Dewidar, 2003; Xu, 2008; Meade \& Moody, 2010; Dai \& Lu, 2014; Jiang et al., 2017; Zhou et al., 2017), and that consequently, $85 \%$ of deltaic systems are experiencing erosion and retreat (Syvitski et al., 2009). For example, Yang et al. (2011) indicated that the Yangze River delta has switched from $\sim 0.13$ billion $\mathrm{m}^{3} / \mathrm{yr}$ of sediment accretion in the 1970 s to $\sim 0.1$ billion $\mathrm{m}^{3} / \mathrm{yr}$ of erosion in recent years, owing to the sharp reduction of river sediment load caused by the operation of Three Gorges Dam. Bi et al. (2014) suggested that the erosion-accretion patterns in the Yellow River Delta (YRD) have changed significantly since initiation of the Water-Sediment Regulation Scheme (WSRS) after 2002, and Ji et al. (2018) suggested that the YRD has been transforming from an accretionary to an erosional state since 2016 because of intensive human intervention. El Banna \& Frihy (2009) documented that at the beginning of $20^{\text {th }}$ century, accretion on the Nile delta switched to erosion, which is attributed primarily to dam construction on the Nile River. As a result of relative sealevel rise, levee and dam construction and delta excavation, the Mississippi River delta has undergone catastrophic drowning over the past eight decades (Nittrouer \& Viparelli, 2014).

Contrary to these and other studies of changes in subaerial and subaqueous delta morphology, deltaic channels have received much less attention. Previous work has focused on morphological adjustment to changes in fluvial water and sediment 
regimes or in sea level (Swenson et al., 2005; Jerolmack, 2009; Dente et al., 2017; Zheng et al., 2017a), or has studied channel avulsion processes and controls (Slingerland \& Smith, 2004; Aslan et al., 2005; Edmonds et al., 2009; Phillips, 2011; Zheng et al., 2018a). A certain amount of fluvial sediment delivery is required, in order to maintain the erosion-accretion balance of deltas (Wang et al., 2006; Nittrouer \& Viparelli, 2014; Wu et al., 2017; Ji et al., 2018), and it has been suggested that a portion of this supply is increasingly sourced by scouring from deltaic channels given severe decreases in sediment delivery from upstream (Wang et al., 2010). Thus, the evolution of deltaic channels is likely to be associated with changes in sediment supply to the delta front.

\subsection{Yellow River Delta and its channels}

The contributions of YRD to biodiversity and human society are significant. The YRD is home to 9.85 million people and contains approximately $4,568 \mathrm{~km}^{2}$ of natural wetlands with important biodiversity hotspots (1,543 wild animal species, 400 seed plant species, and 298 bird species, Jiang et al., 2017). In addition, China's second largest oil field, Shengli Oilfield, is located on the YRD, its estimated reserves of petroleum and natural gas are 4.6 billion tons and 221.3 billion $\mathrm{m}^{3}$, respectively. Therefore, protecting the YRD from various natural and anthropogenic hazards, for example coastal erosion, land subsidence and flooding is important.

Previous studies have shown that patterns of erosion and accretion of the YRD have changed in recent decades, owing to declining water and sediment delivery from upstream. In particular, the transition from a natural to a human-regulated regime, has been associated with a shift from accretion to erosion in both the subaerial delta and the subaqueous delta. Table 1 summarizes the erosion-accretion patterns of the YRD 
and its channels established in previous studies. For the subaerial portion of the YRD, previous work has revealed rapid-accretion occurring at the active Yellow River mouth where there is sufficient sediment supply, and erosion at abandoned river mouths due to sediment starvation, with more complex cycles of erosion and accretion elsewhere (Li et al., 2000; Chu et al., 2006; Cui \& Li, 2011; Xing et al., 2016). For example, four stages in the evolution process of the YRD during 1976-2005 have been observed by Cui \& Li (2011) and a similar result was obtained for the period 1996-2011 by Bi et al. (2014). For the subaqueous portion of the YRD, changes in erosion-accretion patterns generally corresponded with those of the subaerial portion (Bi et al., 2014; Wu et al., 2017; Ji et al., 2018). For example, the bathymetric profiles of a transect off the YRD in the work of $\mathrm{Bi}$ et al. (2014) showed that the subaqueous delta prograded seaward between 1996 and 1998, and then gain between 2002 and 2008, before experiencing significant erosion between 1998 and 2002. Ji et al. (2018) found that the subaqueous delta $\left(37^{\circ} 48^{\prime} \mathrm{N}-37^{\circ} 55^{\prime} \mathrm{N}, 119^{\circ} 10^{\prime} \mathrm{E}\right)$ experienced accretion between 1996 and 2015, except for the period 1998-2001 when erosion occurred at a rate of $0.55 \times 10^{8} \mathrm{~m}^{3} / \mathrm{yr}$, and experienced erosion again, after 2015 at a rate of $0.53 \times 10^{8} \mathrm{~m}^{3} / \mathrm{yr}$.

Compared with numerous investigations of the YRD's erosion and accretion patterns, the deltaic channels have received much less attention, with a focus on qualitative description of long-term evolution and the impacts of reduced fluvial inputs on channel geometry (Shi \& Zhang, 2003; Wang et al., 2006; Wang et al., 2008; Wu et al., 2017; Zheng et al., 2018a). For example, previous work has proved that the Qingshuigou channel's morphology and behaviour varies according to notable changes in upstream water and sediment supply and human activities (Wang et al., 2008; Zheng et al., 2018a). More specifically, based on channel transect form and riverbed longitudinal profile morphology, Wang et al. (2008) argued that there were 
four periods in the evolution process of the lower Qingshuigou channel between 19762000, and Zheng et al. (2018a) identified four similar phases during 1976-2015 (Table 1).

Relatively few previous studies have considered the inter-relationship between YRD channel adjustments and erosion-accretion patterns on the delta front. Zhao (2005) investigated the length of channel influenced by extension of the estuary as the Qingshuigou lobe grew and found this to be $160-170 \mathrm{~km}$ when the estuary extended 28-30km. Zheng et al. (2019) proposed that backwater effects extend no more than $50 \mathrm{~km}$ upstream, except during the flood seasons when this may reach $60 \mathrm{~km}$.

This paper considers changes in deltaic channels and the associations with upstream and downstream drivers of change. The Qingshuigou channel on the YRD offers data of unprecedented detail to investigate these relations. This old channel was reactived in 1976 by human intervention and has remained the primary channel of the delta since then. Geomorphic changes in the distal 110km of the Qingshuigou channel on the YRD were extracted from systematic measurements $(1,410$ in total) of 19 crosssectional profiles (Table 2, Figure 2) between 1976 and 2015. This data set has the potential to provide a fuller, more quantitative assessment of how the Qingshuigou channel has changed in size and geometry. An investigation of spatio-temporal geomorphic adjustment provides insights into the response of deltaic channels to the combined effects of changing upstream water and sediment regimes and intensive engineering activities. One of the outcomes of this work is an ability to better understand how deltaic channels respond to the changes in delta-front erosionaccretion patterns that have previously been identified (Cui \& Li, 2011; Bi et al., 2014; Ji et al., 2018) - an issue returned to in the discussion. 


\section{Regional setting}

\subsection{The Yellow River}

The Yellow River originates on the Qinghai-Tibet Plateau, runs through the Loess Plateau, and then flows eastwards across the North China Plain, finally emptying into the Bohai Sea. The river is $5,464 \mathrm{~km}$ long and drains a catchment of $7.52 \times 10^{5} \mathrm{~km}^{2}$ (Jiang et al., 2017; Ji et al., 2018). Approximately $60 \%$ of the water comes from the upper reaches of the Yellow River (typically regarded as above the Toudaoguai hydrological station, Figure 1A), and over $90 \%$ of the sediment load is provided from the middle reach because of intensive erosion across the Loess Plateau (Figure 1A, Miao et al., 2011; Wang et al., 2017). Historically, many flood disasters occurred in the lower reaches of the river, partly because the gentle terrain and high rates of accretion produced frequent avulsions. Four large reservoirs, partly built to control flood risk became operational between 1960 and 1999 (Figure 1A): from upstream to downstream, Longyangxia (1986, 24.7 billion $\mathrm{m}^{3}$ ), Liujiaxia (1968, 5.7 billion $\mathrm{m}^{3}$ ), Sanmenxia (1960, 36.0 billion $\mathrm{m}^{3}$ ) and Xiaolangdi (1999, 12.65 billion $\mathrm{m}^{3}$ ).

\subsection{The Yellow River Delta}

The Yellow River Delta is fluvially dominated with an irregular semidiurnal tide and a mean tidal range of 1.1-1.5 $\mathrm{m}$. The local sea level rise averaged approximately 3.3 mm/yr between 1980 and 2017 (State Oceanic Administration, China, 2017). The modern YRD has been built by rapid sedimentation and frequent avulsions after a major avulsion in 1855, when the lower Yellow River switched to a more northerly course and emptied into the Bohai Sea (Figure 1). Annual sediment transported to the YRD was 0.677 billion tons during 1950-2016, and between 50 and $70 \%$ of incoming 
sediment was deposited on the delta or near the shoreline due to a weak coastal dynamic environment (Saito et al., 2001; Wang, 2010; Zheng et al., 2018a). The delta progradation rate is about $2-3 \mathrm{~km} / \mathrm{yr}$ at channel mouths and approximately $5,400 \mathrm{~km}^{2}$ of new land has been accreted on the modern YRD since 1855.

Eleven major avulsions occurred, and channel bifurcations were very frequent between 1855 and 1976, forming new fans, floodplain topography and alluvial stratigraphy on the YRD (Zheng et al., 2018a). The primary deltaic channel changed nine times between 1855 and 1953 with the common apex at Ninghai (Ji et al., 2018). After that, the Shenxiangou channel (July 1953-December 1963), the Diaokouhe channel (January 1964-May 1976), and the Qingshuigou channel (May 1976-present) were dominant (Figure 1B), but the latter resulted from human intervention. General instability, with five major bifurcations between 1967 and 1975 plus a large flood in Oct.1975 (maximum discharge of $6,500 \mathrm{~m}^{3} / \mathrm{s}$ at Lijin station) that endangered people and the YRD oilfield, led to a decision by the Yellow River Conservancy Commission (YRCC) to force an avulsion out of the Diaokouhe channel.

From April 1976, water release from the Sanmenxia reservoir was reduced to 500 $\mathrm{m}^{3} / \mathrm{s}$ and water gates (Figure 2B) in Shandong and Henan Provinces were opened to further reduce the flow to the YRD. This allowed construction of a cut-off dam across the Diaokouhe channel (Figure 1C) and excavation of a $250-500 m$ wide, $0.8-3.0 m$ deep and 8,750m long channel near Xihekou to divert flow east, into the Qingshuigou channel, an abandoned channel last occupied between 1889 and 1897 (Figure 1B). The Diaokouhe channel has therefore been abandoned since 1976 (Figure 2C), and the Qingshuigou channel has been heavily managed via construction of levees, farm dikes, country roads and bank protection (Figure 2). 
Later, in 1996 to facilitate oilfield production, flow was diverted again out of the distal portion of the Qingshuigou channel toward the north and into the Q8-Chahe channel, downstream of cross section $38 \mathrm{Q} 8$. This was accomplished by excavating a channel 200m wide, 1.6m deep and 5,000m long (Figure 1D). Additionally, to scour severe sedimentation in the lower Qingshuigou channel, artificial floods have been generated since 2002 by coordinated operation of reservoirs in the middle reaches of the Yellow River. This activity also serves to release sediment from the reservoirs and is referred to as the Water and Sediment Regulation Scheme (WSRS). The WSRS-induced artificial floods are generated in the early part of the natural flood season every year, with a maximum water discharge of $\sim 4,200 \mathrm{~m}^{3} / \mathrm{s}$, which usually lasts for $\sim 20$ days. Approximately $20-46 \%$ of the annual water and sediment discharges are rapidly released from the reservoirs and delivered to the river mouth. In summary, since the artificial avulsion, deltaic channel morphology has been affected by some major human activities: 1) the forced diversions in 1976 and 1996; 2) operation of the Longyangxia and Xiaolangdi reservoirs since 1986 and 1999, respectively; and 3) implementation of the WSRS since 2002.

The deltaic reach of the Yellow River is located downstream of the Lijin hydrological station and along its $110 \mathrm{~km}$ length there are 42 channel cross sections (Figure 2). The profiles of each cross section are generally measured twice per year, before and after the flood season (July-October). The most recent data are from Oct. 2015 and measurements of different cross-sections started in different years. Most crosssections were first measured in 1975/1976, but 30Q4, 33Q6 and 35Q7 were set up in 1977, 1980 and 1982, respectively, while some cross sections have been measured intensively since 2001 or 2004 , respectively. In addition, the orientations of 21CS6, 22CS7 and 24Q1 were adjusted in 2004 to be perpendicular to the main flow. To 
investigate the processes that characterized the Qingshuigou channel's evolution between 1976 and 2015, 19 cross-sections with relatively long time series were chosen, measurements of which are shown in Table 2.

Lijin station is the last hydrological station on the Yellow River, where water discharge and sediment concentration entering the YRD are measured. Between 1976 and 2002, annual water yield $Q_{w}$ and sediment load $Q_{s}$ decreased at an average rate of 1.25 billion $\mathrm{m}^{3} / \mathrm{yr}$ and 0.03 billion $\mathrm{t} / \mathrm{yr}$, respectively (Figure $3 \mathrm{~A}$ ). Average daily discharge in the calendar year $Q_{\mathrm{y}}$ and flood season $Q_{\mathrm{f}}$, and maximum daily discharge for the calendar year $Q_{\max }$ also showed a general decline over this period (Figure 3B). Operation of the WSRS after 2002 led to increases in annual water yield and sediment load, but the rebound of annual water yield was greater than that of sediment load and has been more sustained (Figure 3A). The coefficient $\xi$ is used to describe the general relationship between water and sediment conditions as the ratio of annual average suspended sediment concentration and water discharge. As shown in Figure 3B, $\xi$ increased significantly after the operation of Longyangxia reservoir in 1986 and has tended to be more variable since then. This is consistent with the conclusion of $\mathrm{Ji}$ et al. (2018) that an abrupt change occurred in both the time series of water and sediment discharge after 1985. However, since 2002, operation of the WSRS, has led to a decline in the sediment coefficient $\xi$ as relatively high discharges have dominated.

\section{Methods}

To investigate the evolution of the Qingshuigou channel geomorphology between 1976 and 2015, characteristics that describe the scale, shape and gradation of the main channel have been extracted from the 19 cross-section profiles: width $B$, area 
$A_{\text {mc }}$, width-to-depth ratio $B / H$ and average bed elevation $Z_{b d}$. These parameters were extracted for every measured profile between 1976 and 2015 and because at least two profiles were available in most years, an average value was determined for each year. In total, the four parameters were determined for 1,410 cross-section profiles.

As shown in Figure 4A, channel width $B$ is measured as the horizontal distance between two bank points. The lower of these two elevations is the bank elevation $Z_{\mathrm{bk}}$ and area enclosed by a horizontal line at that elevation and the channel bed is defined as the cross-sectional area $A_{\mathrm{mc}}$. The depth of the main channel $H$ is the ratio of crosssectional area $A \mathrm{mc}$ to its width $B$, and width-to-depth ratio is $B / H$. Average channel bed elevation Zbd is calculated by subtracting the main channel depth $H$ from bank elevation Z bk for each cross-section. Furthermore, rate of change rate $\mathrm{d} x / \mathrm{d} t$ for any given parameter $x=B, A_{\mathrm{mc}}, B / H$ or $Z_{\mathrm{bd}}$, has been estimated as the slope of a linear regression model for linear facets of the time series of $x$. In all cases, $\mathrm{R}^{2}$ coefficients are greater than 0.5 (as in the example shown in Figure 4B). $\mathrm{d} x / \mathrm{d} t>0$ indicates an increase in the parameter through time and $\mathrm{d} x / \mathrm{d} t<0$ represents a decrease through time.

To analyse erosion-accretion patterns in the deltaic channel, sediment annual aggradation/degradation volume, $V\left(10^{8} \mathrm{~m}^{3}\right)$ was estimated as the average change in area each year at consecutive cross-sections multiplied by the distance between them, following Zheng et al. (2018a, b),

$$
V=10^{-5} \sum_{i=1}^{N-1}\left(\frac{\Delta A_{m c, i}+\Delta A_{m c, i+1}}{2} \Delta L_{i, i+1}\right)
$$

where, $N$ is the number of cross-sections; $\Delta A_{m c, i}$ is annual change in cross sectional area of the $i^{\text {th }}$ cross-section $\left(\mathrm{m}^{2}\right) ; \Delta L_{i, i+1}$ is distance between the $i^{\text {th }}$ and $(i+1)^{t h}$ 
cross-sections $(\mathrm{km})$. Sediment mass is calculated as multiply volume by unit weight, which is taken to be $1,300 \mathrm{~kg} / \mathrm{m}^{3}$ (Zheng et al., 2018b).

\section{Results}

4.1 Spatio-temporal variation of the Qingshuigou channel geomorphology

Temporal and spatial variations of channel characteristics are shown in Figure 5. Channel width (Figure 5A) generally increased along the entire reach between 1976 and 1985, except for 3 cross-sections near the avulsion location, which narrowed at up to 196 m/yr. Between 1986 and 1992 width decreased consistently throughout the reach beginning in the downstream reaches and then propagating upstream. Between 1992 and 2002, the pattern of change is characterised by alternating sub-reaches of widening and narrowing that are consistent through time. After 2002, channel width generally increased throughout the whole reach, although at low rates. Channel width decreased in the most distal section of the channel after 2012.

Changes of cross-section area (Figure 5B) show quite distinctive temporal shifts. Immediately after reactivation of the Qingshuigou channel, between 1976 and 1977, area increased upstream of the avulsion and decreased close to it. This was quickly followed by a brief period (1977-1979) of decreasing area upstream of the avulsion and increase downstream. After that, the main channel area responded consistently along the channel length with an alternating pattern of increase and decrease in the periods 1980-1985, 1986-1995, 1996-1998, 1999-2002. After 2002 the pattern becomes less consistent: in general channel cross section area increased, but this was more consistent upstream of the avulsion and after 2012 there is a consistent reduction in area in the distal reaches of the channel. 
Six different time periods of contrasting change in width to depth ratio are clear in the upstream reaches above the avulsion location (Figure 5C). In contrast, changes in $B / H$ are much less consistent downstream of the avulsion, although the main upstream trends are reflected here too. The general pattern soon after the avulsion (1976-1979) was for $B / H$ to increase - the channel became relatively wider. Periods of narrowing, widening and narrowing again occurred sequentially between 1980 and 1996 and in each case the shift in behaviour occurred in the downstream reaches first and propagated upstream. Between 1997 and 2001 there was a shift to widening again which affected the whole channel length simultaneously. Narrowing then dominated between 2002 and 2015 but was more persistent and spatially continuous in the reach upstream of the avulsion.

Changes in bed elevation are characterised by six fairly distinct periods (Figure 5D). Apart from degradation at four upstream cross sections immediately after the avulsion, the initial period between 1976 and 1979 is characterised by aggradation upstream and downstream. Aggradation continues to dominate through the downstream reach until 1994, whereas upstream of the avulsion a period of consistent degradation (1980 to 1985 ) is followed by a period of widespread aggradation (1986-1994). After 1994 trends are more consistent throughout the entire reach, with clear periods of degradation (1995-1997), aggradation (1998-2001) and degradation (2002-2015). An exception is in the most distal reaches where there has been aggradation since 2012 .

Further summarising the information contained in Figure 5, it is apparent that six different time periods characterise the evolution process of the Qingshuigou channel, i.e., 1976-1979, 1980-1985, 1986-1995, 1996-1997, 1998-2001 and 2002-2015. These periods (I to $\mathrm{VI}$, respectively) are described in terms of the general trends in 
morphometric properties in Table 3. For example, changes in channel size, as indicated by $A_{m c}$, followed an alternative pattern of shrinkage and enlargement. The overall aggradation/degradation trend of the whole Qingshuigou channel in these six periods is consistent with changes in channel size, which is an alternative pattern of aggradation and degradation. In addition, the average rates of sediment erosion/deposition in the deltaic channel during different periods are calculated (Figure 8).

In Period I, immediately after the forced avulsion, a distinction is made between subperiods $l_{a}(1976)$ and $l_{b}(1977-1979)$ where some important local effects are evident. In the first year after the avulsion, the channel in the upstream reach widened and deepened, increasing cross-sectional area, while downstream the channel narrowed and shallowed so area diminished (Table 3). This difference in response lasted only for the first year and subsequent channel adjustments were generally consistent upstream and downstream (Table 3).

\subsection{Spatio-temporal variation of cross-section size and shape}

The rates and directions of change in channel area, width and depth can be used to identify eight possible styles of change in cross-section morphology (a-h, Table 4). These styles are focused on cross-section shape and size and do not consider changes in planform style or position. Over the course of the study period, along the entire length of the delta channel, there were no significant changes in planform style. The channel area $\left(A_{\mathrm{mc}}\right)$ may increase or decrease overall and this can be accomplished in four different ways in each case, depending on the relative rates of change in width and depth. Based on calculated rates of change in successive years 
in $\mathrm{d} A \mathrm{mc} / \mathrm{d} t, \mathrm{~d} B / \mathrm{d} t$ and $\mathrm{d} H / \mathrm{d} t$ all cross sections have been categorised according to Table 4. The geomorphological evolution of the Qingshuigou channel in terms of changing cross-sectional area and shape is then summarised in Figure 6. Of the eight styles in Table 4, styles $c$ and $f$ were not apparent in the data set.

Assuming that bank elevation $Z_{b k}$ remains constant, the change in bed elevation is simply the opposite of the change in $H$, as indicated in Table 4. However, our data indicate that at some cross-sections between some occasions, bank elevation did change. In these cases, each cross-section was examined to identify those cases where the change in bed elevation was not simply the opposite of the change in $H$, i.e. where bed elevation dropped despite a reduction in $H$ or where bed elevation increased despite an increase in $\mathrm{H}$. In Figure 6 an asterisk highlights these cases (32\% of the total), essentially showing where the bed elevation moved in the opposite direction to the sketches in Table 4. Figure 6 essentially distils the information in Figure 5 and focuses attention on how channel area and shape, in terms of width-to-depth ratio, have changed in space and time along the channel.

In the reaches upstream of the avulsion the channel widened, shallowed and diminished in cross-sectional area during Period I, and then widened, deepened and grew in area during Period II; i.e. predominantly style $d$ followed by style b. Close to the avulsion, there was narrowing, shallowing and a reduction in cross-sectional area, followed by subsequent increase in area during Period II; i.e. a shift from style $\mathrm{h}$ to style b. Downstream reaches became wider and deeper with increasing width-to-depth ratio in Period I and II (i.e. style a). This widening and deepening propagated 
downstream and replaced style b gradually, indicating a shift to widening over deepening.

During Period III, in the upstream reaches, channel area decreased through shallowing despite some widening and width-to-depth ratio increased (styles $\mathrm{d}$ and $\mathrm{g}$ ). In downstream reaches shrinkage occurred by both narrowing and shallowing, though predominantly narrowing and a reduction in width-to-depth ratio (style h). There is, again a time-transgressive pattern, whereby the switch from increasing to decreasing $B / H$ propagates upstream from cross section 21CS6 so that most of the channel length was characterised by style $\mathrm{h}$ at the end of the period.

During Period IV, channel area increased again, but channel narrowing, or deepening was in excess of widening so $B / H$ declined and bed elevation fell (styles $b$ and e). Channel area decreased and width-to-depth ratio increased during Period V, but this was accomplished via shallowing with widening in the upstream reach (style d) and shallowing with narrowing in the downstream reach (style g).

During Period $\mathrm{VI}$, the upstream cross-sections grew larger by widening and deepening at a greater rate so that width-to-depth ratio decreased (style b). The dominant trend downstream was also channel enlargement but styles e and b (relatively greater deepening) were replaced by style a (relatively greater widening) during this period. This widening trend also moved upstream from cross-section 22CS7 to 17ZJWZ. Toward the end of Period VI channel area declined in the distal reaches as widening became less important than shallowing (style d) although after 2004, the distal reaches were characterised by increasing width-to-depth ratio.

4.3 Spatio-temporal variation of Qingshuigou channel bed elevation and longitudinal profile 
A 3D contour map for average bed elevation of the Qingshuigou channel was constructed using Kriging interpolation of average $Z_{b d}$ values from each cross-section over the study period (Figure 7A). Longitudinal profiles of the Qingshuigou channel at different points in time are shown in Figure 7B, 7C and 7D.

Immediately after the avulsion in Period I, bed levels fell at the site of the avulsion but there was slight aggradation in the upstream reach and more substantial aggradation in the downstream reach, which resulted in a decrease of channel slope from 0.123 per mille to 0.111 per mille. During Period II, degradation characterised the upper reach and the upper part of the downstream reach as far as $60 \mathrm{~km}$, but aggradation dominated in the distal section, leading to a further reduction in overall channel slope to 0.096 per mille. In Period III, bed elevation generally increased and average channel slope was relatively stable at 0.096 per mille. The channel bed then lowered during Period IV, with greater degradation downstream, associated with diversion into the artificial Q8-Chahe channel in 1996, and overall slope increased to 0.110 per mille. Bed elevation was generally stable during Period $V$ except for slight aggradation in the downstream and a decline in channel slope to 0.106 per mille. Over the thirteen years of Period VI, the average bed profile dropped by up to $2 \mathrm{~m}$ but this erosion was greater upstream and channel slope decreased again to 0.097 per mille.

\section{Discussion}

5.1 Geomorphic response of the Qingshuigou channel to human influences

The spatio-temporal analysis of geomorphic change presented in Figures 5 to 7 suggests a six-period characterisation of channel evolution between 1976 and 2015. The first three of these time periods (up to 1996) generally correspond to the evolution 
stages for the lower Qingshuigou channel summarized by Wang et al. (2008) and Zheng et al. (2018a). In contrast to those studies, which identified a single period dominated by human interference after 1996, our systematic quantitative assessment of geomorphic change identified three distinctive periods since 1996 highlighting channel responses to specific human activities.

This section seeks to explain the observed shifts in geomorphological behaviour in light of three major human influences: the engineered avulsion of the main river into the Qingshuigou channel in 1976, the artificial diversion toward the north and into the Q8-Chehe channel in 1996 and changes in water and sediment regime after implementation of the WSRS in 2002. Average water and sediment conditions during Periods I to $\mathrm{VI}$ are provided in Table 5.

The avulsion in 1976 into the Qingshuigou channel shortened the river course and steepened the longitudinal slope, which contributed to upstream channel widening and deepening, growth in cross-sectional area and falling bed levels at the site of the redirection (Figure 6 and 7B). In contrast, eroded sediment from upstream deposited in the reaches downstream of the avulsion (Figure 6). This adjustment lasted only one year at the beginning of Period I. With extension of the river course and sediment accretion in the downstream reaches, especially in the distal reaches, overall longitudinal slope decreased quickly (Figure 7B). Adjustment to the imposed engineering changes therefore happened rapidly in the upstream reaches. Close to and upstream of the avulsion the channel shallowed and narrowed or shallowed in excess of widening (Figure 6). This infilling may also reflect abundant fine sediment influx $\left(Q_{s}=0.90\right.$ billion $t, D_{50}=0.017 \mathrm{~mm}$ ) with relatively small water discharge ( $Q_{y}$ 
$\left.=971 \mathrm{~m}^{3} / \mathrm{s}\right)$ in Period I (Table 5). The reactivated channel downstream of the avulsion grew throughout, accompanied by aggradation (Figure 6).

In Period II, average annual water yield increased by $17 \%$ while average annual sediment load decreased by $13 \%$ compared with fluxes in Period I, and the coefficient $\xi$ decreased (Table 5). The channel widened, deepened and increased in crosssectional area during Period II (Figure 6) and this propagated downstream with a shift from dominant deepening to dominant widening consistent with the decreasing specific stream power along the reach. Furthermore, average bed elevation in the downstream channel continued to rise, which contributed to continued decline of longitudinal slope (Figure 7B). Similar channel morphological evolution in the downstream reaches during this period and in Period I (Figure 6), demonstrate that development of the channel downstream of the avulsion was a spatio-temporal process propagating away from the avulsion site over time to its downstream. This development process lasted until 1985 after which water and sediment conditions have tended to be more variable (Figure 3).

During Period III, average annual water yield and sediment load decreased by $51 \%$ and $42 \%$ compared with Period II, and sediment coefficient $\xi$ increased from 0.020 to 0.049 (Table 5). Water and sediment conditions during this period promoted aggradation, adding to the decrease of longitudinal slope in the previous two periods. The channel became smaller along the whole reach, but changes in channel shape varied. Decreasing fluvial inputs through time (Figure 3 and Table 5) were responsible for a time-transgressive pattern from increasing to decreasing width-to-depth ratio that propagated from 21CS6 upstream (Figure 6). Additionally, during Period III, longitudinal slope was generally consistent (Figure 7C) suggesting that the longitudinal slope of the Qingshuigou channel was reaching to equilibrium state. In this period, 
adjustment to the channel avulsion was less important than changes in the water and sediment regime for channel evolution.

Fluvial input decreased further in Period IV, average annual water yield and sediment load decreased by $51 \%$ and $50 \%$ compared with Period III, and sediment coefficient $\xi$ increased dramatically (Table 5). Further channel shrinkage might be anticipated, but channel area increased (Figure 6), because the artificial diversion of 1996 shortened the distal course of the channel. Channel width-to-depth ratio declined by channel narrowing or deepening in excess of widening (Figure 6B) and bed elevation fell, especially in the distal reaches (Figure 7C). So that longitudinal slope increased slightly (Figure 7C). In this period, adjustment to the human intervention dominates but, as in Period I this lasted only one to two years.

During Period V, fluvial inputs decreased further (Table 5) and channel shrinkage returned. Channel geomorphic change was generally similar to that in Period III (Figure 6), except that was a trend of bed accretion from downstream to upstream (Figure 7D). That may reflect readjustment to the equilibrium slope that emerged in Period III (0.096 per mille), following the slight increase in slope caused by the artificial avulsion in Period IV. In Period V, water and sediment regimes still controlled channel geomorphology with consistent trends in morphological change along the reach, but with some spatial differences (styles $\mathrm{d}$ and $\mathrm{g}$ ) which possibly reflect pre-existing local topography.

The WSRS was implemented in 2002 and average annual water yield increased by $161 \%$ while average sediment load generally stayed at the same level as in Period V, such that the sediment coefficient $\xi$ decreased dramatically from 0.073 in Period $V$ to 0.019 in Period VI (Table 5). This was accompanied, in the upstream reaches by channel widening and deepening but with decreasing width-to-depth ratio, except 
downstream, where cross-sectional area increased with widening in excess of channel deepening (Figure 6). The average bed profile dropped by up to $2 \mathrm{~m}$ in thirteen years during this period, with more degradation upstream such that channel slope decreased again to 0.097 per mille (Figure 7D). Channel shape changes were different upstream and downstream which may reflect a combination of fluvial and coastal influences. Toward the end of Period VI channel area declined in the distal reaches as widening became less important than shallowing after 2004 (Figure 6). These patterns are unusual compared with the general geomorphic evolution of the Qingshuigou channel in earlier periods, which may be due to the changing erosion-accretion patterns on the YRD.

The patterns of evolution identified in this paper differ from those in other studies, which considered evolution of subaerial and/or subaqueous portions of the Yellow River (Kong et al., 2015; Jiang et al., 2017; Wu et al., 2017; Ji et al., 2018; Zhang et al., 2018). For example, Wu et al. (2017) found that the subaerial and subaqueous portions of the Yellow River experienced four periods of development: channel and floodplain deposition and rapid seaward progradation of the delta lobe in the first period of 1976-1981, delta lobe progradation during the second period of 1981-1996, net delta erosion between 1996-2002, and slight accretion of the subaerial delta in the recent period of 2002-2013. Nevertheless, as one portion of the deltaic system, the evolution of the deltaic channel, subaerial delta and subaqueous delta of the Yellow River are all impacted by fluvial water and sediment supply, as well as human interventions. As documented by previous work, channel shifts and altered water and sediment regime induced by the WSRS have affected the evolution of YRD significantly (Li et al., 2000; Jiang et al., 2017; Wang et al., 2017; Ji et al., 2018; Wu et al., 2020). For example, because of the diversion in 1996, the Q8-Chahe distal 
channel (Figure 2) was enlarged (Figure 5B) whereas the abandoned Qingshuigou channel has received over $20 \mathrm{~cm}$ of sedimentation (Wu et al., 2020). Moreover, because of the implementation of WSRS, the Qingshuigou channel incised and deepened between 2002-2015 rather than shrinking as between 1985-1996 (Zheng et al., 2018a), and the subaerial delta of the Yellow River shifted from slow erosion during 1996-2002 to slow accretion during 2002-2013 (Wu et al., 2017). Although evolution of the delta front has not been considered when identifying stages in the evolution process of the Qingshuigou channel, the six-period spatio-temporal model of change in channel geometry provides insights into the response of deltaic channels to the combined effects of changing upstream water and sediment regimes and intensive engineering activities.

The evolution of channel geomorphology has been observed in other rivers worldwide (Makaske et al., 2002; Aslan et al., 2005; Phillips, 2011; Zheng et al., 2017b), as well as in some flume experiments (Edmonds et al., 2009; Reitz et al., 2010). It starts with channel avulsion when flow escapes from its old channel and carves a new path or reactivates an abandoned path (Slingerland \& Smith, 2004; Aslan et al., 2005). Immediately after avulsion, this new, lower channel is typically subject to rapid accretion, followed by incision and erosion. As the channel progrades seaward, the longitudinal slope and specific stream power decrease, leading to channel backfilling and the formation of an alluvial ridge. Avulsion occurs when critical conditions are attained, and the whole process repeats at a new delta lobe (Zheng et al., 2018a). Because of fewer human interventions, geomorphic evolution in Periods I to III of the Qingshuigou channel in this study is similar to this natural process.

With intensifying human activities, changes in channel geomorphology can be triggered not only by internal autogenic mechanisms but also by external disturbances 
(Simon \& Darby, 2002; Zheng et al., 2017b). For example, in addition to initial, and relatively short-lived, adjustments to major engineering interventions (Periods $l_{a}$ and IV), changes in channel geomorphology have been affected by the water and sediment regimes of the Yellow River, as affected by the WSRS (Periods V and VI), as well as by local topographic variations along the reach. Many studies have documented the effects of human activities on deltas and channel morphological adjustments (Syvitski \& Saito, 2007; El Banna \& Frihy, 2009; Syvitski et al., 2009; Jiang et al., 2017; Zhou et al., 2017; Zhou et al., 2018). Syvitski et al. (2009) found that many deltas are sinking $\left(8 \mathrm{~mm} / \mathrm{yr}\right.$ on the YRD) in the $21^{\text {st }}$ century, and human activities are largely responsible for the vulnerability of deltas. The number of natural distributary channels on deltas has often been reduced artificially, to fix deltaic channels' location and protect populated areas by levees (Syvitski \& Saito, 2007). A common consequence is superelevation of the riverbed above the delta floodplain. In combination, processes of delta subsidence and channel bed aggrading are a threat to deltas and the societies and ecosystems that they support. With continued intensification of human activities (land use change, construction of dams and reservoirs, oil and gas extraction) alongside, sea level rise and more frequent extreme events caused by global warming, this bleak scenario will be exacerbated. Additionally, it should be noticed that the heavily managed and stabilized deltaic channel (for example, the Qingshuigou channel here) cannot respond naturally to extreme events or adjust to broader driving forces, and so will require ongoing and potentially unsustainable management going forward.

5.2 Possible inter-relations between delta-front erosion-accretion patterns and aggradation/degradation in the deltaic channel 
The evolution of channel and delta morphology is intimately connected, change in either part is a potential cause of change in the other (Wang et al., 2006; Syvitski \& Saito, 2007). Previous work has revealed that erosion-accretion patterns of the YRD changed in recent years. Channel area declined in the distal reaches at the end of Period $\mathrm{VI}$, this unusual situation may result from changing erosion-accretion patterns on the delta front. To analyse the response of the deltaic channel to delta-front erosion and accretion, we compared changes in the Qingshuigou channel, with previously reported erosion-accretion on the subaerial and subaqueous parts of the delta (Figure 8). There is relatively little information about the subaqueous delta before 1996, but the available data suggests an accretionary state between 1976 and 1995 (Wu et al., 2017).

Sediment load to the delta front was more than $4.36 \times 10^{8} \mathrm{t} / \mathrm{yr}$ (sediment transport rate in Period III) during Periods I to III, which was sufficient to maintain the delta front. With the rapid decline of fluvial sediment supply after 1996 , only $2.41 \times 10^{8} \mathrm{t} / \mathrm{yr}$ of sediment was delivered to the delta front in Period IV. The subaerial delta experienced scour, leading to slight accretion of the subaqueous delta. Fluvial sediment supply declined further in Period $\mathrm{V}$ to $1.45 \times 10^{8} \mathrm{t} / \mathrm{yr}$, and both the subaerial and subaqueous parts of the delta were eroded. Thereafter, $1.48 \times 10^{8} \mathrm{t} / \mathrm{yr}$ of sediment has been transported to the delta front in Period VI. Although this is little different from the supply in Period V, both the subaerial and subaqueous parts of the delta accreted. This suggests that erosion-accretion patterns of the YRD have changed since 2002.

The relations between delta-front erosion-accretion patterns and events in the deltaic channel is hard to discern because the interactions between fluvial and coastal dynamics are complex. According to the analysis in section 5.1, there were no external 
drivers of channel change in Periods II and VI, and water and sediment conditions were the dominant controlling factor. Furthermore, incoming sediment coefficient $\xi$ and the median diameter of suspended sediment $D_{50}$ in these two periods were generally similar (Table 5). Thus, comparison of channel geomorphology in these two periods may address the question of how changing delta-front erosion-accretion patterns affect the deltaic channel. All else being equal, a lower sediment load with greater water yield is likely to cause more erosion in the deltaic channel (Wang, 2010), so that erosion rate is proportional to $Q_{w} / Q_{s}$. Sediment load and water yield were 0.141 billion t/yr and 17.6 billion $\mathrm{m}^{3} / \mathrm{yr}$ in Period VI and 0.786 billion t/yr and 36.0 billion $\mathrm{m}^{3} / \mathrm{yr}$ in Period II, respectively (Table 5). The deltaic channel might then be expected to erode at a rate of $0.172 \times 10^{8} \mathrm{t} / \mathrm{yr}$ in Period VI compared with $0.063 \times 10^{8} \mathrm{t} / \mathrm{yr}$ in Period II (Figure 8), but the recorded erosion rate was lower, at $0.072 \times 10^{8} \mathrm{t} / \mathrm{yr}$. This discrepancy between observed channel erosion rate compared with a higher estimate based on water and sediment supply, is difficult to explain. It is accompanied by increasing width-to-depth ratio and increasing bed elevation in the downstream reaches (Figures 6 and 7D) that are contrary to the general trends. There is no engineering intervention nor any other obvious upstream control. Coarsening of the river bed is possible given the overall drop in river bed elevation along the study reach between Period II and the end of Period VI, and this may have contributed to reduced bed mobility, but this is uncertain. In sum, these observations point towards the possibility of downstream control in Period VI that reflects changing erosion-accretion patterns on the delta front. Further work is required to understand the relations between delta-front erosionaccretion patterns and delta channel change.

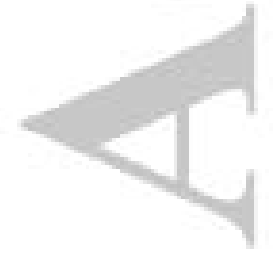

This article is protected by copyright. All rights reserved. 


\section{Conclusions}

Using data from 1976 to 2015, spatio-temporal geomorphic adjustment along a

$\sim 110 \mathrm{~km}$ deltaic reach on the YRD has been analysed. The main conclusions drawn from this investigation are as follows:

(1) Considering rates and directions of change in channel area, width and depth, eight possible styles of change in cross-section morphology have been summarised (Table 4). These styles emphasize the continuous adjustment process of channel geomorphology and may be useful in other analysis based on cross-sectional measurements.

(2) Spatio-temporal changes in the Qingshuigou channel can be described in terms of six time periods (Periods I (1976-1979), II (1980-1985), III (1986-1995), IV (19961997), V (1998-2001) and VI (2002-2015)). In general, changes in key controlling variables as a function of human intervention result in immediate changes in channel geomorphology. For example, the channel upstream of the 1976 avulsion and the 1996 artificial diversion were eroded for $\sim 1-2$ years, owing to respective shortening of the river course. Adjustments along the reach are determined by interactions of the fluvial inputs and direct human interventions that affect channel alignment, slope and dimensions. For example, development of the channel downstream of the 1976 avulsion was a process propagating downstream from the avulsion site over time (Periods I and II). Changes in channel geomorphology also can be variations in the supply of water and sediment to the delta apex. For example, the channel generally widened and deepened in Periods II and VI, owing to increased water yield and decreased sediment supply whereas it tended to narrow and shallow in Periods III and V, because of insufficient sediment load and reductions in water discharge. The occurrence of the opposite trend of increased 
width-to-depth ratio and bed elevation rise in the middle and distal reaches during

Period $\mathrm{VI}$ is contrary to the general evolution, which may reflect changing patterns of erosion-accretion on the delta. It should be clear that the heavily managed and stabilized deltaic channel that we have investigated here cannot adjust naturally to external events, not at least more extreme events driven by continued subsidence and climate change, and so will require ongoing and potentially unsustainable management going forward.

(3) Comparison of erosion-accretion patterns for different parts of the YRD (i.e., in the deltaic channel, on the subaerial part of the delta and the subaqueous part of the delta) showed that when fluvial sediment load to the delta front was less than $1.45 \times 10^{8} \mathrm{t} / \mathrm{yr}$ between 1976-2002, erosion occurred on both the subaerial delta and subaqueous delta. However, similar levels of sediment delivery to the delta after 2002 caused accretion. Furthermore, an estimate of the erosion rate in the deltaic channel during Period VI by making comparison of fluvial input in Period II and VI, was greater than the observed erosion rate, which cannot be explained by any upstream controls. Changing delta-front erosion-accretion patterns may have played an important role in the geomorphic evolution of the deltaic channel between 2002 and 2015. This aspect of delta behaviour requires further investigation.

\section{Acknowledgements}

This study was funded by National Key R\&D Program of China (2017YFC0405502) and National Natural Science Foundation of China (Grant No. 51779183). We appreciate the Yellow River Conservancy Commission for providing the data used in this study. 


\section{Data availability statement}

The data sets used and/or analyzed during the current study are available from the corresponding author on reasonable request.

\section{Statement on conflicts of interest}

The authors declare no conflicts of interest.

\section{Reference}

[1] Aslan A, Autin WJ, Blum MD. (2005) Causes of river avulsion: insights from the late Holocene avulsion history of the Mississippi River, USA. Journal of Sedimentary Research 75 (4), 650-664.

[2] Bi NS, Wang HJ, Yang ZS. (2014) Recent changes in the erosion-accretion patterns of the active Huanghe (Yellow River) delta lobe caused by human activities. Continental Shelf Research 90, 70-78.

[3] Chu ZX, Sun XG, Zhai SK, Xu KH. (2006) Changing pattern of accretion/erosion of the modern Yellow River (Huanghe) subaerial delta, China: based on remote sensing images. Marine Geology 227 (1-2), 13-30.

[4] Cluer B, Thorne CR. (2014) A stream evolution model integrating habitat and ecosystem benefits. River Research and Applications 30(2): 135-154.

[5] Cui BL, Li XY. (2011) Coastline change of the Yellow River estuary and its response to the sediment and runoff (1976-2005). Geomorphology 127(1), 32-40.

[6] Dai SB, Lu XX. (2014) Sediment load change in the Yangtze River (Chang jiang): a review. Geomorphology 215, 60-73. 
[7] Dente E, Lensky NG, Morin E, Grodek T, Sheffer NA, Enzel Y. (2017) Geomorphic response of a low-gradient channel to modern, progressive base-level lowering: Nahal HaArava, the Dead Sea. Journal of Geophysical Research: Earth Surface $122,2468-2487$.

[8] Edmonds DA, Hoyal D, Sheets B, Slingerland RL. (2009) Predicting delta avulsions: implications for coastal wetland restoration. Geology 37 (8), 759-762.

[9] El Banna MM, Frihy OE. (2009) Human-induced changes in the geomorphology of the northeastern coast of the Nile delta, Egypt. Geomorphology 107, 72-78.

[10] Fagherazzi S, Edmonds DA, Nardin W, Leonardi N, Canestelli A, Falcini F, Jerolmack DJ, Mariotti G, Rowland JC, Slingerland RL. (2015) Dynamics of river mouth deposits. Reviews of Geophysics 53, 642-672.

[11] Frihy OE, Dewidar KM. (2003) Patterns of erosion/sedimentation, heavy mineral concentration and grain size to interpret boundaries of littoral sub-cells of the Nile Delta, Egypt. Marine Geology 199, 27-43.

[12] Gu YZ, Jiang MX, Xu CL, Chen JQ, Huo JX. (2000) The impact on the project of the Yellow River estuary Qing 8 and its influence on estuary evolution. Journal of Sediment Research 57-61 (in Chinese).

[13] Jerolmack DJ. (2009) Conceptual framework for assessing the response of delta channel networks to Holocene sea level rise. Quaternary Science Reviews $28(17), 1786-1800$.

[14] Ji HY, Chen SL, Pan SQ, Xu CL, Jiang C, Pan YS. (2018) Morphological variability of the active Yellow River mouth under the new regime of riverine delivery. Journal of Hydrology 564, 329-341. 
[15] Jiang C, Pan S, Chen S. (2017) Recent morphological changes of the Yellow River (Huanghe) submerged delta: causes and environmental implications. Geomorphology 293.

[16] Kong DX, Miao CY, Borthwick AGL, Duan QY, Liu H, Sun QH, Ye AZ, Di ZH, Gong W. (2015) Evolution of the Yellow River Delta and its relationship with runoff and sediment load from 1983 to 2011. Journal of Hydrology 520, 157-167.

[17] Li G, Zhuang K, Wei H. (2000) Sedimentation in the Yellow River Delta. Part III. Seabed erosion and diapirism in the abandoned subaqueous delta lobe. Marine Geology 168 (1), 129-144.

[18] Makaske B, Smith DG, Berendsen HJA. (2002) Avulsions, channel evolution and floodplain sedimentation rates of the anastomosing upper Columbia River, British Columbia, Canada. Sedimentology 49 (5), 1049-1071.

[19] Meade RH, Moody JA. (2010) Causes for the decline of suspended-sediment discharge in the Mississippi River system, 1940-2007. Hydrological Processes 24, 35-49.

[20] Miao CY, Ni JR, Borthwick AGL, Yang L. (2011) A preliminary estimate of human and natural contributions to the changes in water discharge and sediment load in the Yellow River. Global and Planetary Change 76 (3-4), 196-205.

[21] Nienhuis JH, Ashton AD, Giosan L. (2016) Littoral steering of deltaic channels. Earth and Planetary Science Letters 453, 204-214.

[22] Nittrouer JA, Viparelli E. (2014) Sand as a stable and sustainable resource for nourishing the Mississippi river delta. Nature Geoscience 7(5), 350-354.

[23] Phillips JD. (2011) Universal and local controls of avulsions in southeast Texas Rivers. Geomorphology 130 (1-2), 17-28. 
[24] Reitz MD, Jerolmack DJ, Swenson JB. (2010) Flooding and flow path selection on alluvial fans and deltas. Geophysical Research Letters 37 (6), 6401.

[25] Saito Y, Yang Z, Hori K. (2001) The Huanghe (Yellow River) and Changjiang (Yangtze River) deltas: a review on their characteristics, evolution and sediment discharge during the Holocene. Geomorphology 41 (2), 219-231.

[26] Shi CX, Zhang D. (2003) Processes and mechanisms of dynamic channel adjustment to delta progradation: the case of the mouth channel of the Yellow River, China. Earth Surface Processes and Landforms 28 (6), 609-624.

[27] Simon A, Darby SE. (2002) Effectiveness of grade-control structures in reducing erosion along incised river channels: the case of Hotophia Creek, Mississippi. Geomorphology 42: 229-254.

[28] Slingerland RL, Smith ND. (2004) River avulsions and their deposits. Annual Review of Earth and Planetary Sciences 32 (32), 257-285.

[29] Swenson JB, Paola C, Pratson L, Voller VR, Murray AB. (2005) Fluvial and marine controls on combined subaerial and subaqueous delta progradation: morphodynamic modeling of compound-clinoform development. Journal of Geophysical Research Atmospheres 110 (2).

[30] Syvitski JPM, Saito Y. (2007) Morphodynamics of deltas under the influence of humans. Global and Planetary Change 57(3-4), 0-282.

[31] Syvitski JP, Kettner AJ, Overeem I, Hutton EW, Hannon MT, Brakenridge GR, Day J, Vörösmarty C, Saito Y, Giosan L. (2009) Sinking deltas due to human activities. Nature Geoscience 2, 681-686.

[32] Tejedor A, Longjas A, Zaliapin I, Foufoula-Georgiou E. (2015) Delta channel networks: A graph-theoretic approach for studying connectivity and steady state transport on deltaic surfaces. Water Resources Research 51(6), 3998-4018. 
[33] Walling DE, Fang D. (2003) Recent trends in the suspended sediment loads of the world's rivers. Global and Planetary Change 39, 111-126.

[34] Wang HJ, Bi NS, Saito Y, Wang Y, Sun XX, Zhang JM, Yang ZS. (2010) Recent changes in sediment delivery by the Huanghe (Yellow River) to the sea: causes and environmental implications in its estuary. Journal of Hydrology (Amsterdam) 391(3-4), 302-313.

[35] Wang HJ, Wu X, Bi NS, Li S, Yuan P, Wang AM, Syvitski JPM, Saito Y, Yang ZS, Liu SM, Nittrouer J. (2017) Impacts of the dam-orientated water-sediment regulation scheme on the lower reaches and delta of the Yellow River (Huanghe): a review. Global \& Planetary Change 157, 93-113.

[36] Wang KC. (2010) Evolution and Management of the Yellow River Delta. Yellow River Water Conservancy Press, Zhengzhou (in Chinese).

[37] Wang KR, Huang HJ, Zhang YP. (2008) Shrinkage on riverbed form of the tail of Yellow River mouth in Qingshuigou course. Marine Geology and Quaternary Geology 28(2): 15-22 (in Chinese).

[38] Wang S, Hassan MA, Xie X. (2006) Relationship between suspended sediment load, channel geometry and land area increment in the Yellow River Delta. Catena $65(3), 302-314$

[39] Wang ZY, Liang ZY. (2000) Dynamic characteristics of the Yellow River mouth. Earth Surface Processes and Landforms 25 (7), 765-782.

[40] Wu X, Bi NS, Xu JP, Nittrouer JA, Yang ZS, Saito Y, Wang HJ. (2017) Stepwise morphological evolution of the active Yellow River (Huanghe) delta lobe (19762013): dominant roles of riverine discharge and sediment grain size. Geomorphology 292, 115-127. 
[41] Wu X, Wang HJ, Bi NS, Nittrouer JA, Xu JP, Cong S, Carlson B, Lu TA, Li ZY. (2020) Evolution of a tide-dominated abandoned channel: A case of the abandoned Qingshuigou course, Yellow River. Marine Geology 422,106-116.

[42] Xing GP, Wang HJ, Yang ZD, Bi NS. (2016) Spatial and temporal variation in erosion and accumulation of the subaqueous Yellow River Delta (1976-2004). Journal of Coastal Research 74 (74), 32-47.

[43] Xu JX. (2008) Response of land accretion of the Yellow River Delta to global climate change and human activity. Quaternary International 186 (1), 4-11.

[44] Yang SL, Milliman JD, Li P, Xu K. (2011) 50,000 dams later: erosion of the Yangtze River and its delta. Global and Planetary Change 75, 14-20.

[45] Zhang XD, Lu ZY, Jiang SH, Chi WQ, Zhu LH, Wang HM, Lv K, Wang BY, Yang ZS. (2018) The progradation and retrogradation of two newborn Huanghe (Yellow River) Delta lobes and its influencing factors. Marine Geology 400, 38-48.

[46] Zhao LJ. (2005) Research on the interaction between the lower Yellow River reaches evolution and estuary evolution of Yellow River. Wuhan University (in Chinese).

[47] Zheng S, Wu BS, Wang KR, Tan GM, Han SS, Thorne CR. (2017a) Evolution of the Yellow River Delta, China: impacts of channel avulsion and progradation. International Journal of Sediment Research (1), 34-44.

[48] Zheng S, Thorne CR, Wu BS, Han SS. (2017b) Application of the stream evolution model to a volcanically disturbed river: The North Fork Toutle River, Washington State, USA. River Research and Applications 33(2).

[49] Zheng S, Han SS, Tan GM, Xia JQ, Wu BS, Wang KR, Edmonds DA. (2018a) Morphological adjustment of the Qingshuigou channel on the Yellow River Delta and factors controlling its avulsion. Catena 166, 44-55. 
[50] Zheng S, Wu BS, Zhao YJ, Wang KR, Han SS. (2018b) Erosion and aggradation processes and calculation method for the Qingshuigou channel on the Yellow River Delta. Advances in Water Science 29 (3): $322-330$ (in Chinese).

[51] Zheng S, Edmonds DA, Wu BS, Han SS. (2019) Backwater controls on the evolution and avulsion of the Qingshuigou channel on the Yellow River Delta. Geomorphology 333, 137-151.

[52] Zhou MR, Xia JQ, Lu JY, Deng SS, Lin FF. (2017) Morphological adjustments in a meandering reach of the middle Yangtze River caused by severe human activities. Geomorphology 285, 325-332.

[53] Zhou MR, Xia JQ, Deng SS, Lu JY, Lin FF. (2018) Channel adjustments in a gravel-sand bed reach owing to upstream damming. Global and Planetary Change $170,213-220$. 


\section{Table 1 Erosion-accretion patterns of the YRD and its channels during different}

\section{periods, identified in previous work}

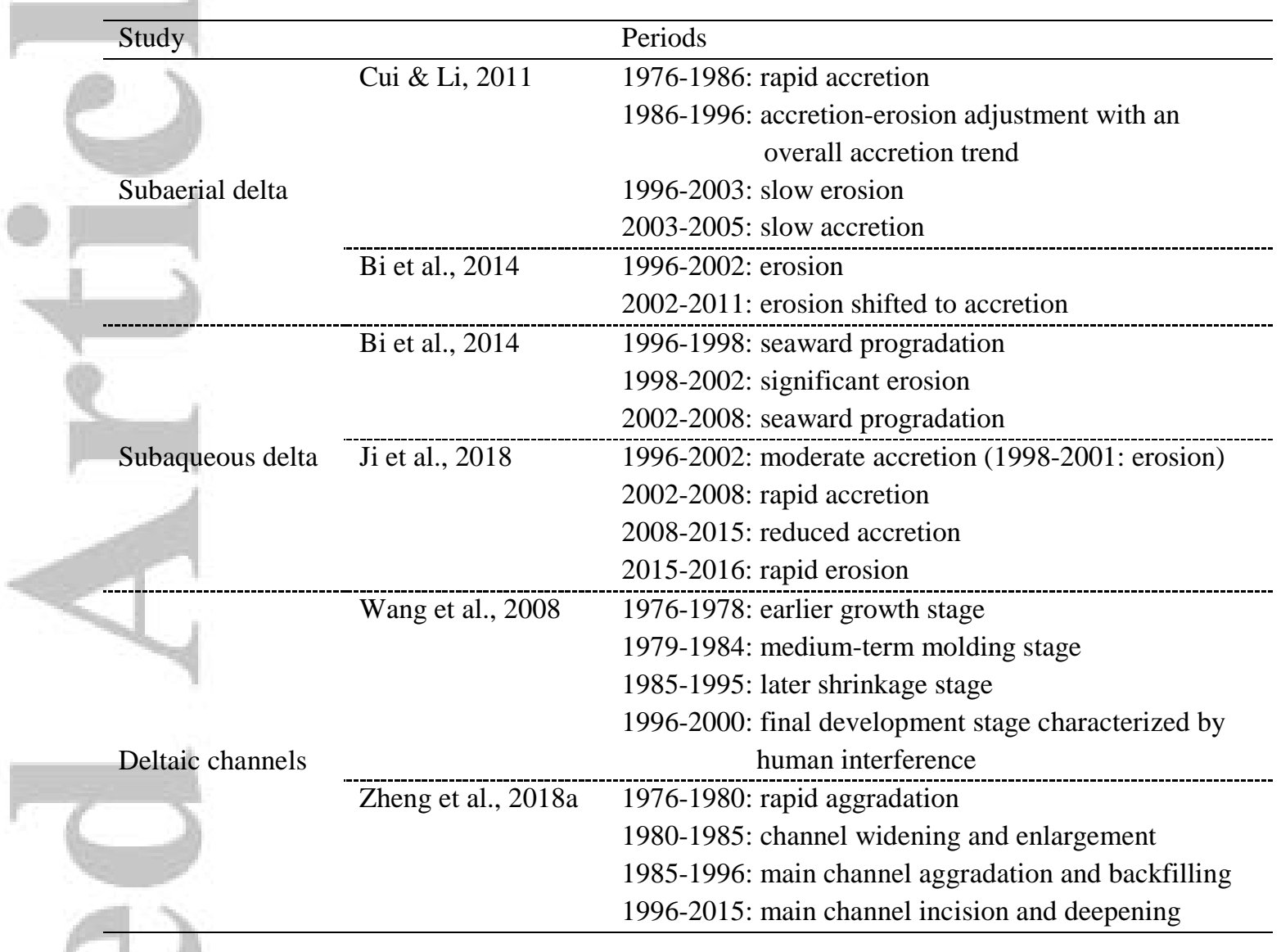


Table 2 Measurements of cross sections used in this study on the recent lobe of the Yellow River Delta

\begin{tabular}{|c|c|c|c|c|c|c|c|c|c|c|c|}
\hline \multirow[b]{2}{*}{ Number } & \multicolumn{3}{|c|}{ Cross sections } & \multicolumn{2}{|l|}{ Measurements } & \multirow[b]{2}{*}{ Number } & \multicolumn{3}{|c|}{ Cross sections } & \multicolumn{2}{|l|}{ Measurements } \\
\hline & Name & $\begin{array}{c}\text { Abbreviated } \\
\text { name }\end{array}$ & $\begin{array}{c}\text { Distance } \\
\text { downstream from } \\
\text { Lijin }(\mathrm{km})\end{array}$ & Period & Times & & Name & $\begin{array}{l}\text { Abbreviated } \\
\text { name }\end{array}$ & $\begin{array}{c}\text { Distance } \\
\text { downstream } \\
\text { from Lijin }(\mathrm{km}) \\
\end{array}$ & Period & Times \\
\hline 1 & Lijin & $\mathrm{LJ}$ & 0.00 & $18 / 06 / 1975-12 / 10 / 2015$ & 86 & 24 & Qing1 & Q1 & 52.01 & $25 / 04 / 1976-16 / 10 / 2015$ & 82 \\
\hline 5 & Wangjiazhuang & WJZ & 9.14 & $20 / 06 / 1975-13 / 10 / 2015$ & 86 & 26 & Qing2 & Q2 & 58.85 & $11 / 06 / 1976-17 / 10 / 2015$ & 82 \\
\hline 8 & Dongzhang & DONGZ & 15.12 & $21 / 06 / 1975-14 / 10 / 2015$ & 86 & 28 & Qing3 & Q3 & 65.13 & 11/06/1976-17/10/2015 & 82 \\
\hline 11 & Zhangqiuwuzi & ZQWZ & 21.76 & $21 / 06 / 1975-14 / 10 / 2015$ & 86 & 30 & Qing4 & Q4 & 70.77 & $17 / 06 / 1977-20 / 10 / 2015$ & 80 \\
\hline 13 & Yihaoba & YHB & 27.49 & $21 / 06 / 1975-14 / 10 / 2015$ & 86 & 33 & Qing6 & Q6 & 77.53 & $22 / 04 / 1980-21 / 10 / 2015$ & 74 \\
\hline 15 & Qianzuo & QZ & 31.59 & $23 / 06 / 1975-15 / 10 / 2015$ & 86 & 35 & Qing7 & Q7 & 82.95 & 17/04/1982-21/10/2015 & 67 \\
\hline 17 & Zhujiawuzi & ZJWZ & 35.35 & $22 / 06 / 1975-15 / 10 / 2015$ & 86 & 39 & Cha1 & $\mathrm{C} 1$ & 88.78 & $21 / 10 / 2001-22 / 10 / 2015$ & 31 \\
\hline 19 & Yuwa & YW & 40.93 & $21 / 06 / 1975-16 / 10 / 2015$ & 86 & 41 & Cha2 & $\mathrm{C} 2$ & 92.03 & $21 / 10 / 2001-22 / 10 / 2015$ & 31 \\
\hline 21 & CS6 & CS6 & 46.26 & $22 / 06 / 1975-16 / 10 / 2015$ & 84 & 42 & Cha3 & $\mathrm{C} 3$ & 94.32 & $25 / 04 / 2004-22 / 10 / 2015$ & 25 \\
\hline 22 & $\mathrm{CS} 7$ & $\mathrm{CS} 7$ & 48.34 & $22 / 06 / 1975-16 / 10 / 2015$ & 84 & & & & & & \\
\hline
\end{tabular}

This article is protected by copyright. All rights reserved. 
Table 3 Geomorphic change of the Qingshuigou channel during different time periods

\begin{tabular}{|c|c|c|c|c|c|c|c|c|c|c|c|c|c|c|}
\hline \multirow{2}{*}{\multicolumn{2}{|c|}{ Time period }} & \multicolumn{6}{|c|}{ Upstream of the 1976 forced avulsion } & \multicolumn{7}{|c|}{ Downstream of the 1976 forced avulsion } \\
\hline & & $B \quad A_{\mathrm{mc}}$ & $H$ & $B / H$ & $Z_{\mathrm{bd}}$ & Shape & $\mathrm{X}-\mathrm{S}$ area & $B$ & $A_{\mathrm{mc}}$ & $H$ & $B / H$ & $Z_{\mathrm{bd}}$ & Shape & $\mathrm{X}-\mathrm{S}$ area \\
\hline $\mathrm{I}$ & $1976-1979$ & + & - & + & + & widening, shallowing & diminish & + & - & - & + & + & widening, shallowing & diminish \\
\hline $\bar{I}_{\mathrm{a}}$ & 1976 & + & + & + & + & widening>deepening & enlarge & - & - & - & + & + & narrowing $<$ shallowing & diminish \\
\hline $\mathrm{I}_{\mathrm{b}}$ & $1977-1979$ & + & 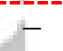 & + & + & widening, shallowing & diminish & + & - & - & + & + & widening, shallowing & diminish \\
\hline II & $1980-1985$ & + & + & - & - & widening $<$ deepening & enlarge & + & + & + & - & - & widening $<$ deepening & enlarge \\
\hline III & $1986-1995$ & - & - & - & + & narrowing >shallowing & diminish & - & - & - & - & + & narrowing $>$ shallowing & diminish \\
\hline IV & 1996-1997 & $t$ & + & - & - & narrowing, deepening & enlarge & - & + & + & - & - & narrowing, deepening & enlarge \\
\hline $\mathrm{V}$ & $1998-2001$ & - & - & + & + & narrowing $<$ shallowing & diminish & - & - & - & + & - & narrowing $<$ shallowing & diminish \\
\hline VI & $2002-2015$ & + & + & - & - & widening<deepening & enlarge & + & + & + & - & - & widening $<$ deepening & enlarge \\
\hline
\end{tabular}

Note: blue character shows bed elevation $Z_{\mathrm{bd}}$ increased despite an increase in depth $H$, owing to changing $Z_{\mathrm{bk}}$. 
Table 4 Eight possible styles of cross-section adjustment over time, based on relative rates of change in cross-section area and shape

\begin{tabular}{lllllll}
\hline Style & $B$ & $A_{\mathrm{mc}}$ & $H$ & $B / H$ & $Z_{\mathrm{bd}}$ & Description \\
\hline (a) & + & + & + & + & - & +
\end{tabular}

Direction of change through time is indicated as - decrease and + increase. In the sketches, the black line shows the original channel and the red dashed line shows the channel after adjustment. 
Table 5 Water and sediment conditions during different time periods

\begin{tabular}{ccccccccc}
\hline \multicolumn{2}{c}{ Time period } & $\begin{array}{c}Q_{\mathrm{w}} \\
\text { billion } \mathrm{m}^{3} / \mathrm{yr}\end{array}$ & $\begin{array}{c}Q_{\mathrm{s}} \\
\text { billion } \mathrm{t} / \mathrm{yr}\end{array}$ & $\begin{array}{c}Q_{\mathrm{y}} \\
\mathrm{m}^{3} / \mathrm{s}\end{array}$ & $\begin{array}{c}Q_{\mathrm{f}} \\
\mathrm{m}^{3} / \mathrm{s}\end{array}$ & $\begin{array}{c}Q_{\max } \\
\mathrm{m}^{3} / \mathrm{s}\end{array}$ & $\begin{array}{c}\xi \\
-\end{array}$ & $\begin{array}{c}D_{50} \\
\mathrm{~mm}\end{array}$ \\
\hline I & $1976-1979$ & 30.6 & 0.901 & 971 & 1949 & 5255 & 0.036 & 0.017 \\
II & $1980-1985$ & 36.0 & 0.786 & 1140 & 2293 & 5425 & 0.020 & 0.023 \\
III & $1986-1995$ & 17.6 & 0.456 & 558 & 977 & 3160 & 0.049 & 0.016 \\
IV & $1996-1997$ & 8.7 & 0.227 & 275 & 616 & 2389 & 0.103 & 0.018 \\
V & $1998-2001$ & 6.7 & 0.150 & 214 & 372 & 1571 & 0.073 & 0.023 \\
VI & $2002-2015$ & 17.6 & 0.141 & 558 & 875 & 3393 & 0.019 & 0.022 \\
\hline
\end{tabular}

Note: $Q_{\mathrm{w}}$-average annual water yield, $Q_{\mathrm{s}}$-average annual sediment load, $Q_{\mathrm{y}}$ and $Q_{\mathrm{f}}$-average daily water discharge in whole year and in the flood season, respectively, $Q_{\max }$-maximum daily water discharge in whole year, $\xi$ incoming sediment coefficient, $D_{50}$-the median diameter of suspended sediment. 


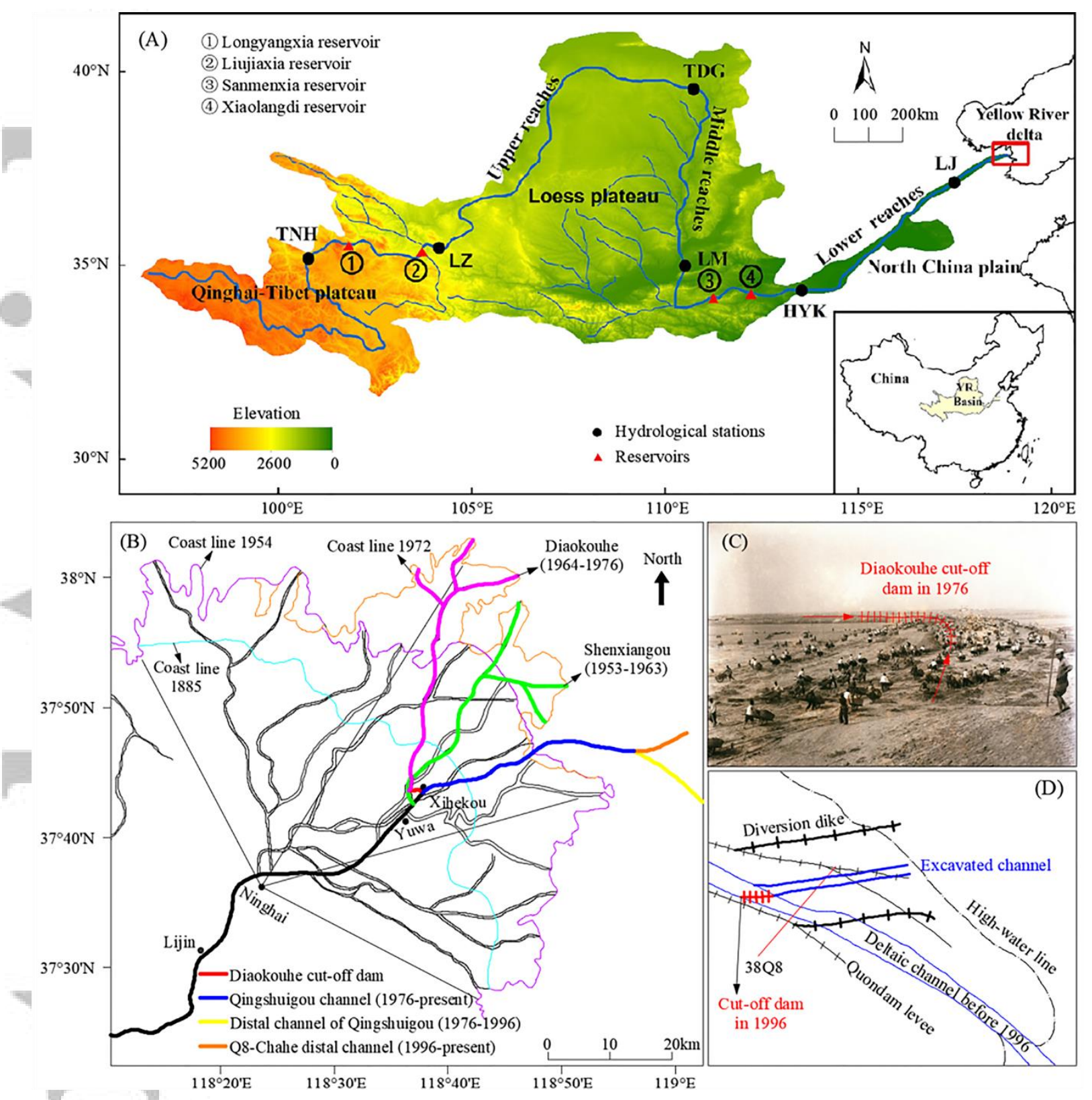

Figure 1 Modern Yellow River Delta. (A) Yellow River basin (modified after Ji et al., 2018), where black dots represent five key hydrological stations (TNH-Tangnaihai, LZLanzhou, TDG-Toudaoguai, LM-Longmen, HYK-Huayuankou, LJ-Lijin); (B) delta lobes at the YRD since 1855 (modified after Wang \& Liang, 2000); (C) cut-off dam construction across the Diaokouhe channel in 1976 (download from http://www.yellowriver.gov.cn/special/rmzlhh70/jcsj/201608/t20160818_167637.html); (D) sketch of the Q8 diversion project (modified after Gu et al., 2000). 


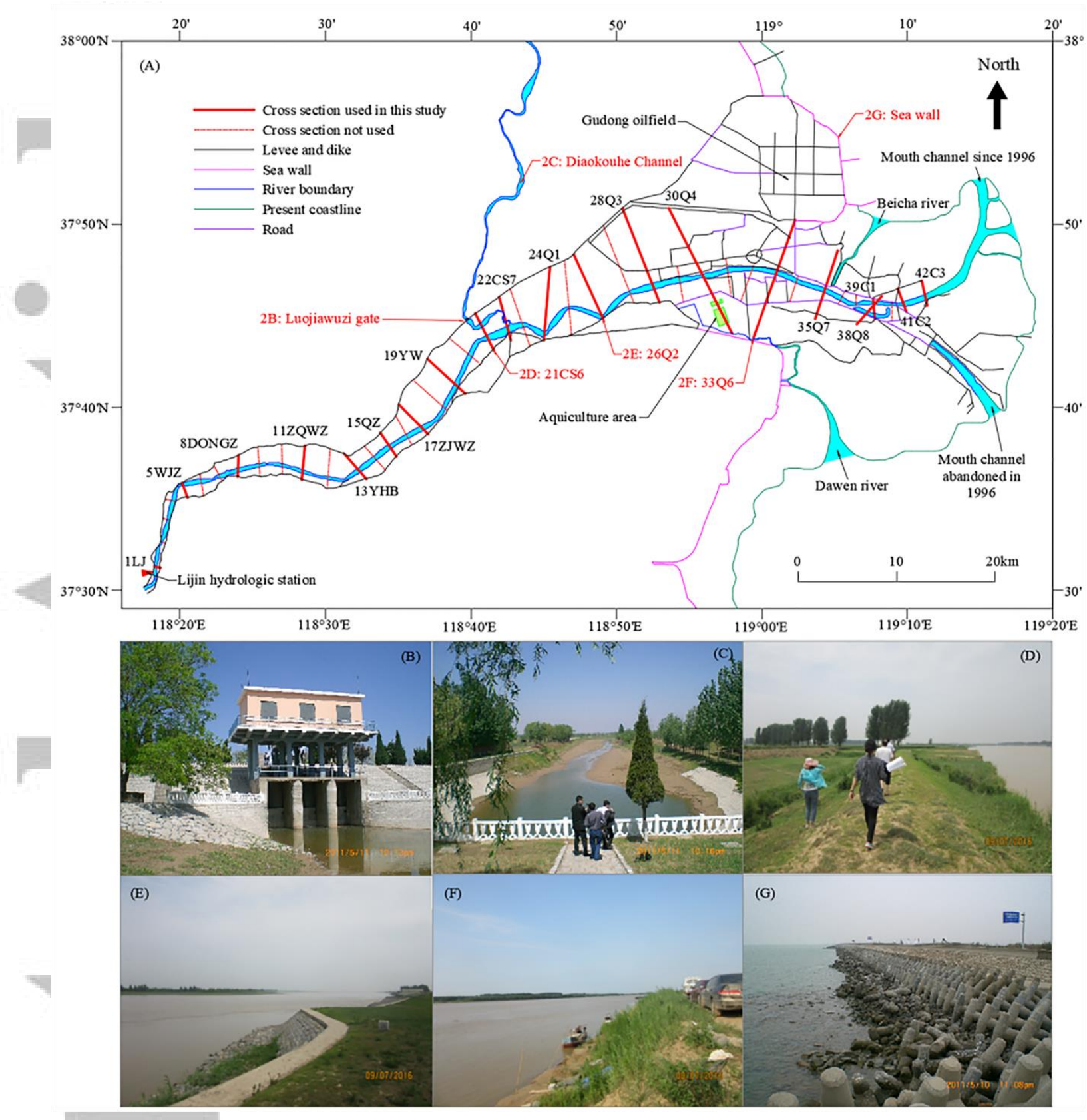

Figure 2 Study area. (A) map of deltaic channel and cross-sections on the YRD (modified from map of the YRD in 2015 by Yellow River Delta Hydrological and Water Resources Survey); (B) Luojiawuzi gate; (C) Diaokouhe channel near the Luojiawuzi gate; (D) farm dike near 21CS6; (E) revetment and river training work at 26Q2 crosssection; (F) country road at the left bank of 33Q6; (G) sea wall near Gudong oilfield. Photos 2B, 2C and 2G were took in May 2011 by the fourth author, photos 2D, 2E and $2 \mathrm{~F}$ were took in July 2016 by the first and fifth author.

This article is protected by copyright. All rights reserved. 


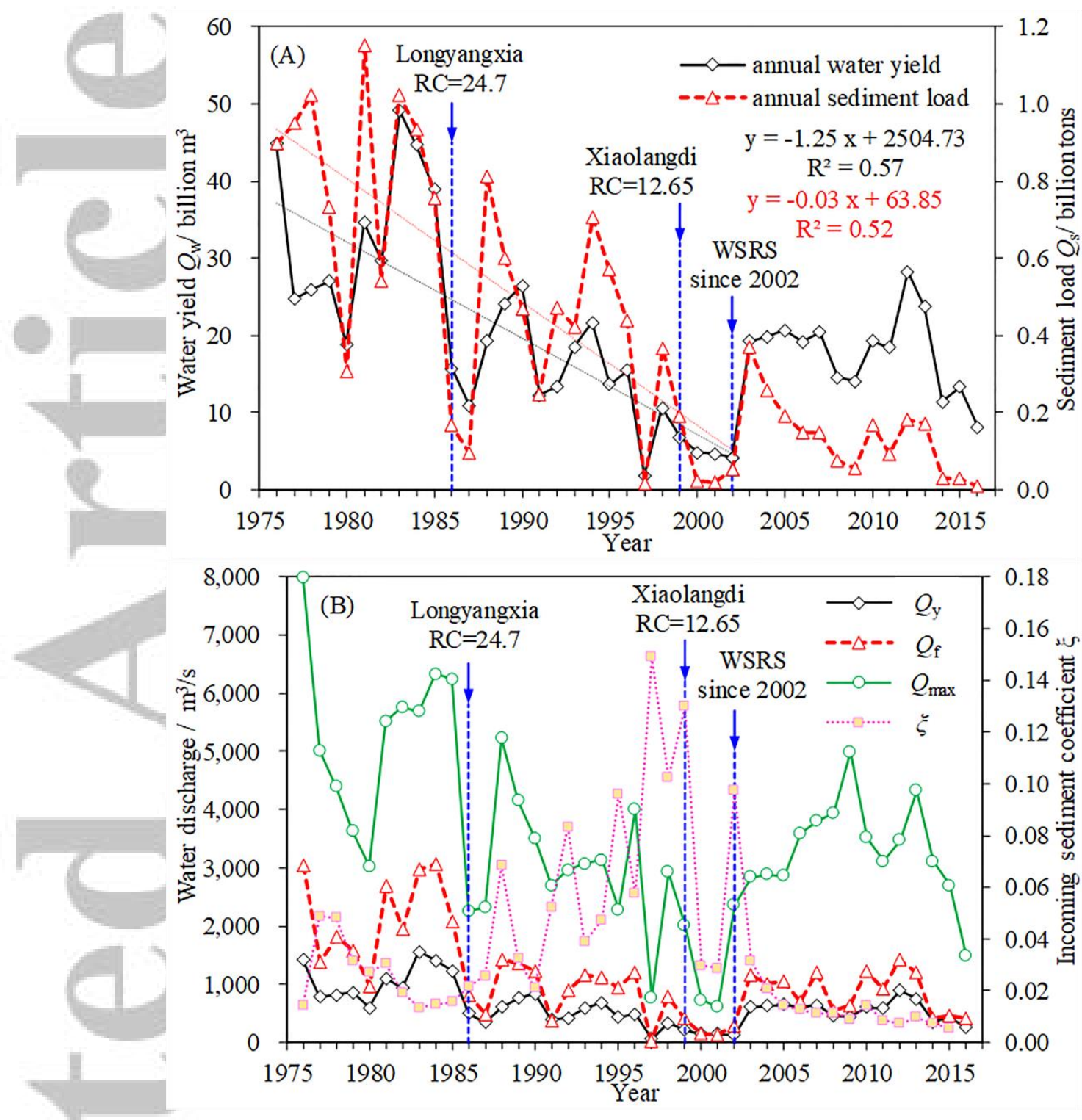

Figure 3 Water and sediment regime at Lijin station 1976-2016. (A) annual water yield and sediment load, (B) average daily discharge for the calendar year $Q_{y}$ and in the flood season $Q_{\mathrm{f}}$, maximum daily discharge for the calendar year $Q_{\max }$, and incoming sediment coefficient $\xi$. Longyangxia and Xiaolangdi reservoirs have been operated since 1986 and 1999, respectively (RC-reservoir capacity, billion $\mathrm{m}^{3}$ ) and the Water and Sediment Regulation Scheme (WSRS) was implemented in 2002.

This article is protected by copyright. All rights reserved. 

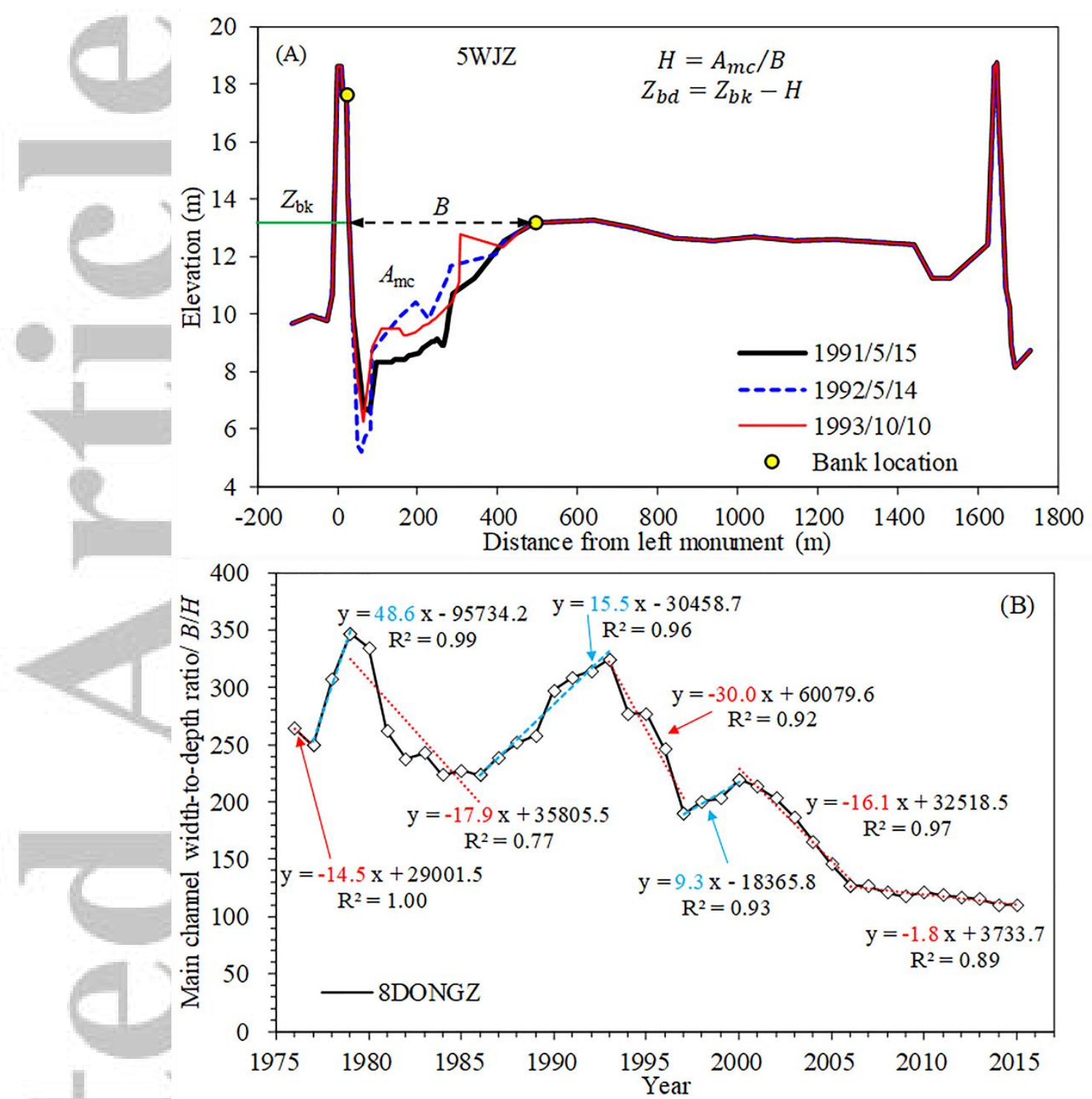

Figure 4 Geomorphic measurements. (A) definition sketch for calculation of main channel width $B$, cross-sectional area $A_{\mathrm{mc}}$, bank elevation $Z_{\mathrm{b} k}$, channel depth $H=$ $A_{m c} / B$, average bed elevation $Z_{b d}=Z_{b k}-H$ and main channel width to depth ratio = $B / H$. Cross-section $5 W J Z$ is used as an example. (B) change rate calculation, taking width-to-depth ratio of cross-section 8DONGZ as an example, slopes of the regression lines are taken as change rates in different periods, which are shown in Figure 5.

This article is protected by copyright. All rights reserved. 

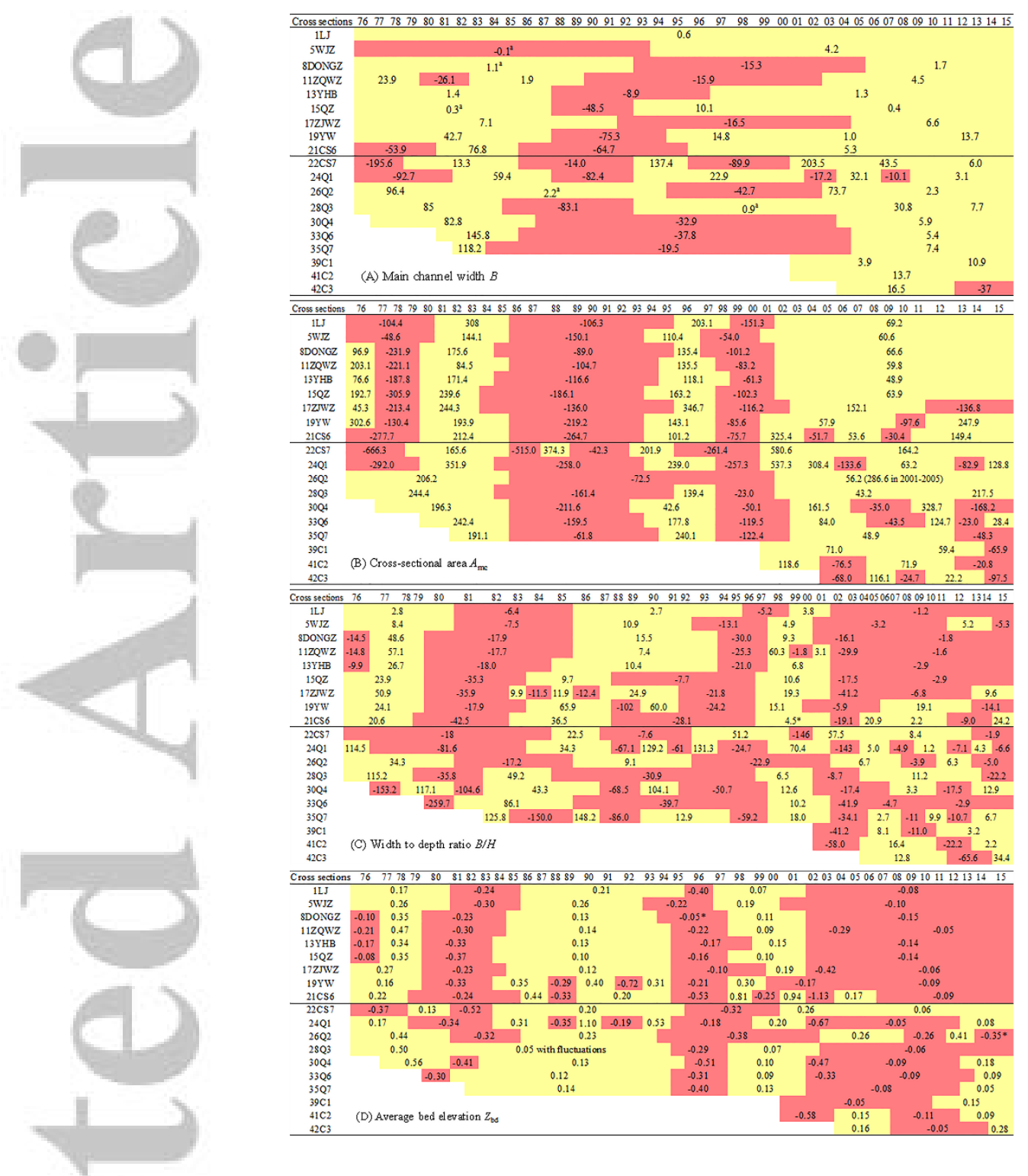

Figure 5 Rates of change of geomorphic parameters through time (horizontal axis, older to more recent is from left to right) and space (vertical axis, top to bottom is upstream to downstream). (A) main channel width $B$; (B) cross-sectional area $A_{\mathrm{mc}}$; (C) width-to-depth ratio $B / H$ and $(D)$ average bed elevation $Z$ bd. Numbers in the figure are rates of change $\mathrm{d} x / \mathrm{d} t\left(x=B, A_{\mathrm{mc}}, B / H\right.$ and $\left.Z_{\mathrm{bd}}\right)$. An increasing trend $\mathrm{d} x / \mathrm{d} t>0$ is shaded yellow and a decreasing trend $\mathrm{d} x / \mathrm{d} t<0$ is shaded red. The horizontal line represents the location of the major artificial diversion between cross-sections 21CS6 and 22CS7 that reoccupied the Qingshuigou channel in 1976. Superscript $\left({ }^{a}\right)$ in Figure (A) indicates change rate calculated by using the first and the last years' data in the period. And an asterisk $\left(^{*}\right)$ in Figure (B) and (D) indicates decision coefficient $0.4<R^{2}<0.5$. 


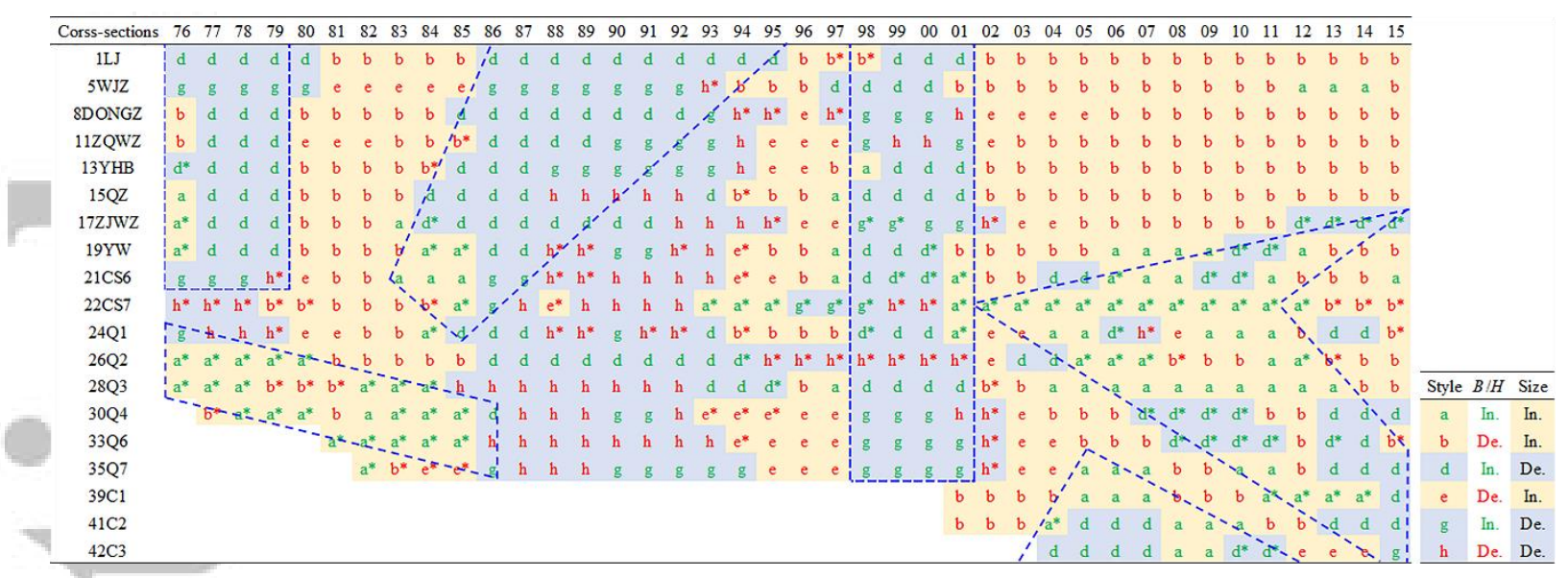

Figure 6 Temporal and spatial variation of the Qingshuigou channel geomorphology. Letters $a$ to $h$ refer to the styles of cross-section change defined in Table 4. Shape changes in terms of an increase or decrease in width-to-depth ratio $(B / H)$ are represented by green and red characters, respectively. The polygons defined by dashed lines highlight times and places where width to depth ratio increased. Enlargement or shrinkage in cross-sectional area $\left(A_{\mathrm{mc}}\right)$ is represented by yellow and blue backgrounds, respectively. An asterisk $\left(^{*}\right)$ indicates a cross-section where the bed elevation moved in the opposite direction to that shown in the sketches in Table 4 (see text).

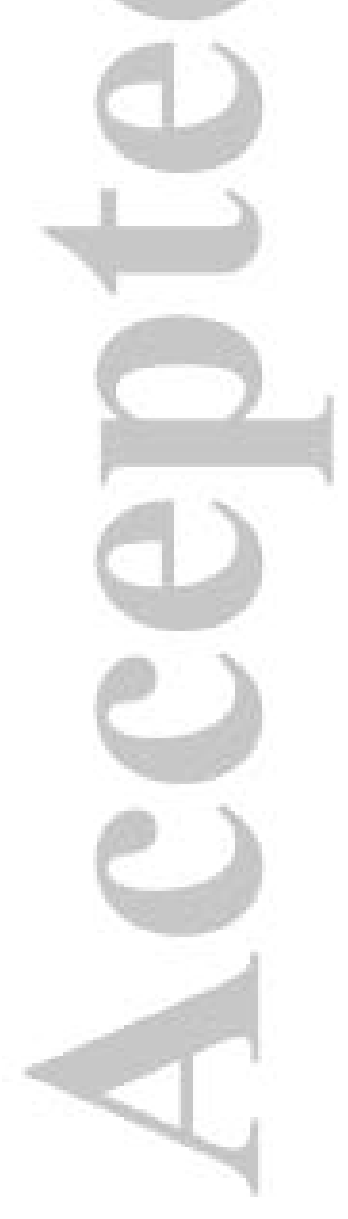

This article is protected by copyright. All rights reserved. 

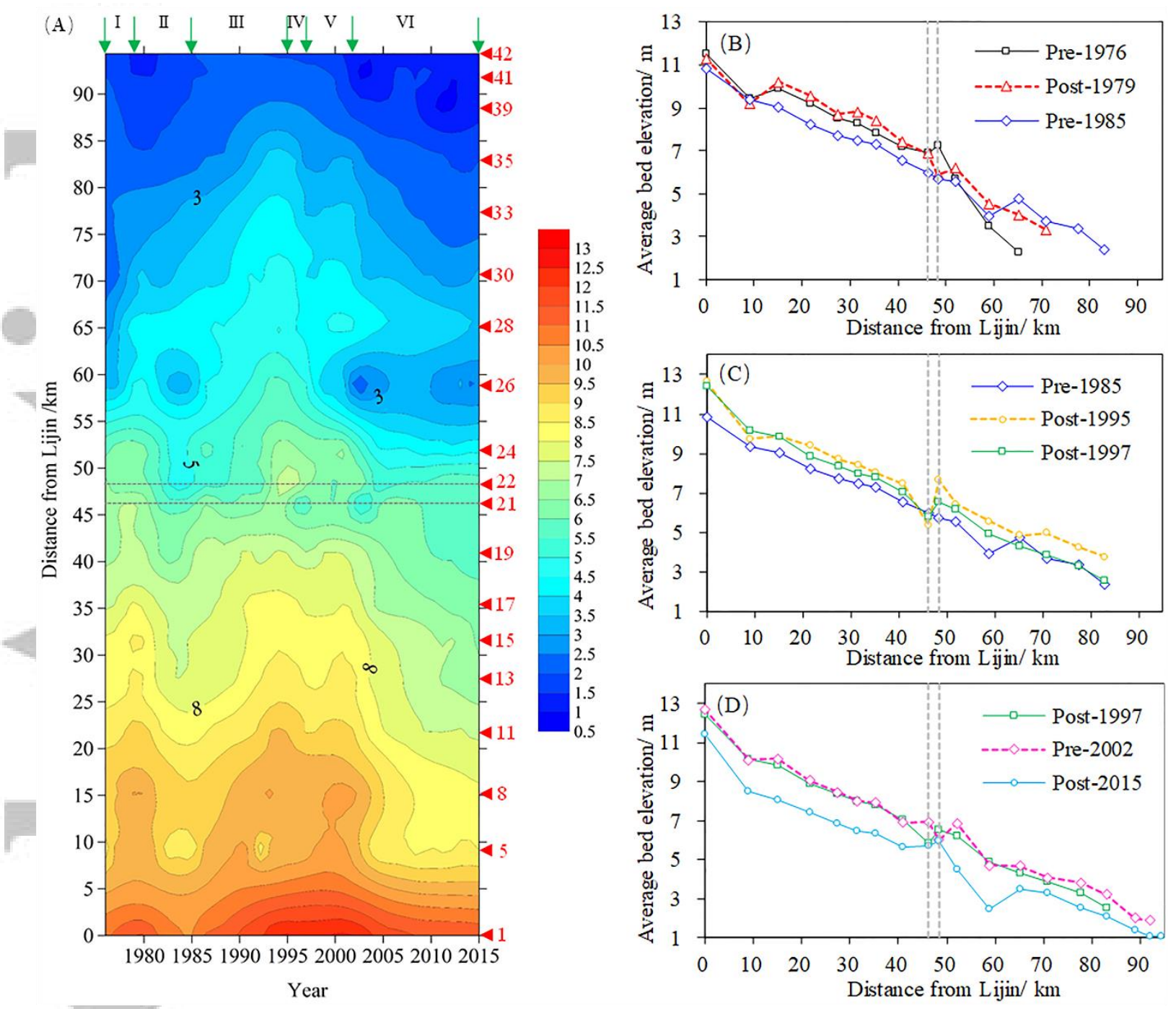

Figure 7 Spatio-temporal variation in average bed elevation $Z_{b d}$ along the Qingshuigou channel between 1976 and 2015. (A) 3D contour map. Red arrows show locations of cross-sections and green arrows correspond to the longitudinal profiles shown in panels $B$ to $D$. (B-D) longitudinal profiles for different points in time. The two gray dashed lines indicate the location of the forced avulsion in 1976. Pre-year and Postyear represent longitudinal profiles before and after the flood season, respectively. 


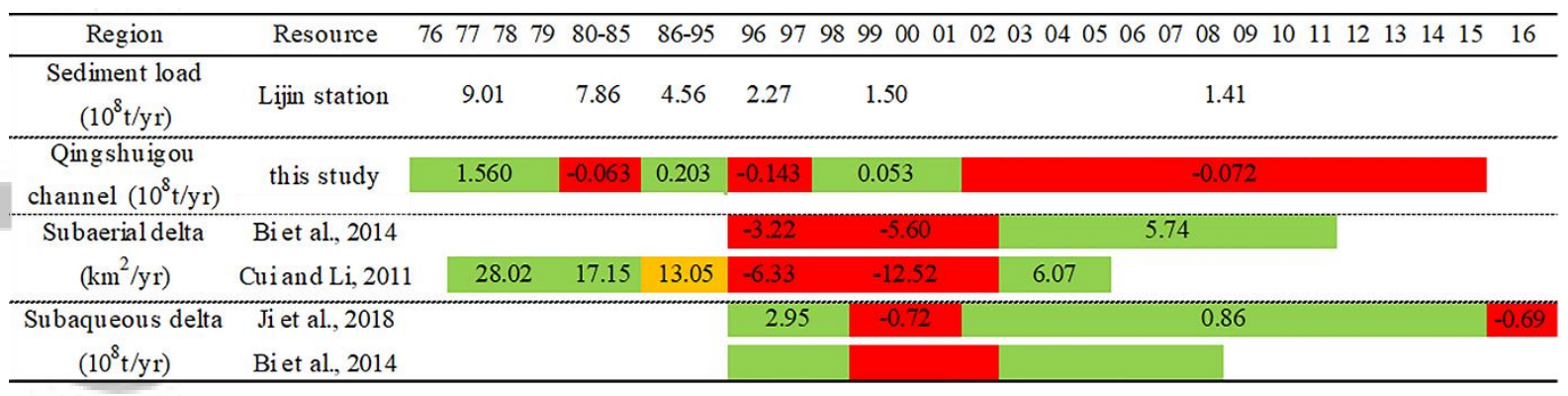

Figure 8 Fluvial sediment load and erosion-accretion patterns on different parts of the YRD between 1976 and 2016. Red and green backgrounds indicate erosion and accretion, respectively, and the yellow background indicates an adjustment period. Numbers are average annual erosion/accretion rates for the periods coloured. Negative numbers represent erosion and positive numbers represent accretion. Data for the delta is from Table 2 of Cui \& Li (2011), Figure 3 of Bi et al. (2014) and Table 3 of $\mathrm{Ji}$ et al. (2018). There are no values of change rate of subaqueous delta in the study of Bi et al. (2014) because only one transect bathymetric data is used. 


\section{Geomorphic evolution of the Qingshuigou channel of the Yellow River Delta in}

response to changing water and sediment regimes and human interventions

Shasha Han, Stephen Rice, Guangming Tan*, Kairong Wang and Shan Zheng

Spatial-temporal morphological change along the Qingshuigou channel of the Yellow River Delta has been quantified using characteristics that describe crosssection dimensions and shape, longitudinal gradation and sediment budget. Distinctive periods of channel change are identified, and analysis provides a detailed understanding of the temporal and spatial adjustments of the channel to specific human interventions, including two artificial channel diversions and changes in water and sediment supply driven by river management, and downstream delta-front development.

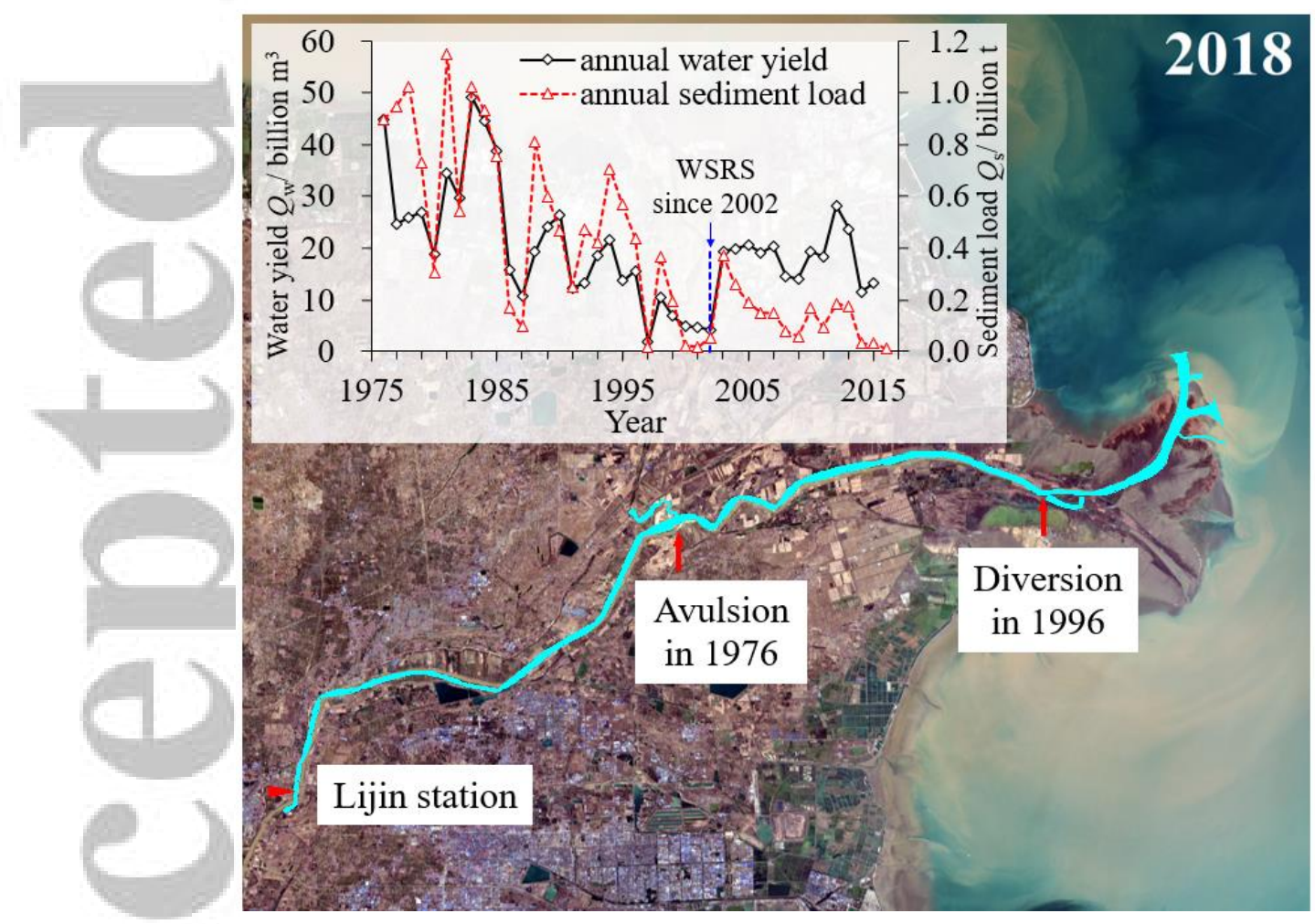

This article is protected by copyright. All rights reserved. 